\title{
Detection and quantification of non-labelled polystyrene nanoparticles using a fluorescent molecular rotor
}

\author{
Angélique Moraz ${ }^{a}$ and Florian Breider $\mathrm{a}^{*}$ \\ a Ecole Polytechnique Fédérale de Lausanne - EPFL, Central Environmental Laboratory, IIE, ENAC, station 2, \\ $\mathrm{CH}-1015$ Lausanne, Switzerland \\ *Corresponding author: Dr. Florian Breider, Ecole Polytechnique Fédérale de Lausanne - EPFL, Central \\ Environmental Laboratory, IIE, ENAC, station 2, CH-1015 Lausanne, Switzerland. e-mail: florian.breider@epfl.ch
}

\section{Table of Content}

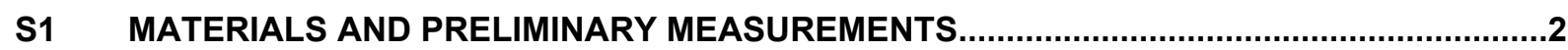

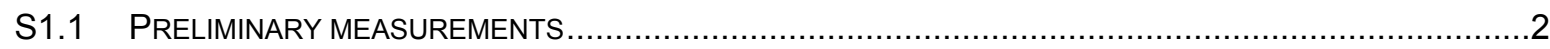

S2 METHOD DEVELOPMENT - PSNS QUANTIFICATION USING DCVJ FLUORESCENCE .....4

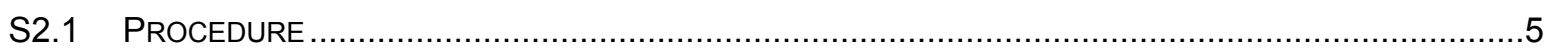

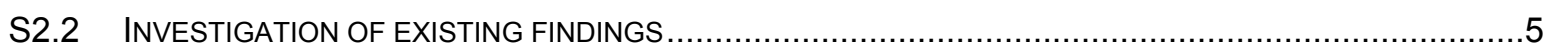

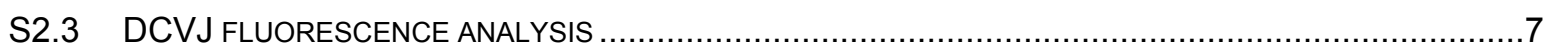

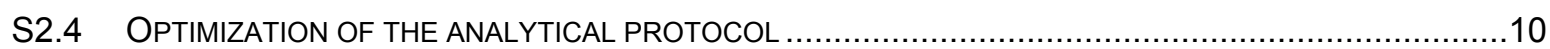

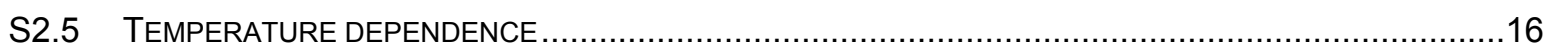

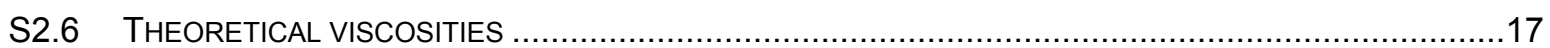

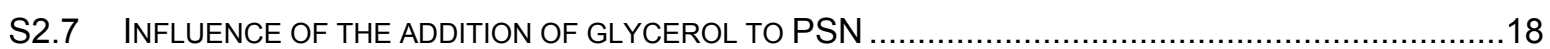

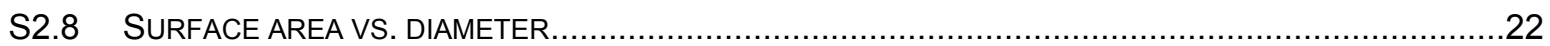

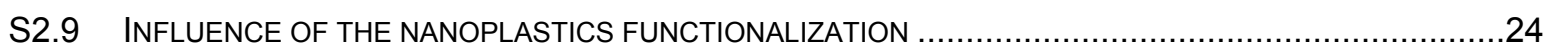

S2.10 PSN QUANTIFICATION IN WATER AND INFLUENCE OF THE NATURAL ORGANIC MATTER .................25

S3 METHOD APPLICATION - PSNS QUANTIFICATION IN BIOLOGICAL SAMPLES.............28

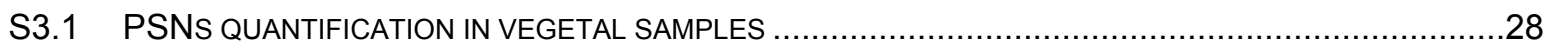

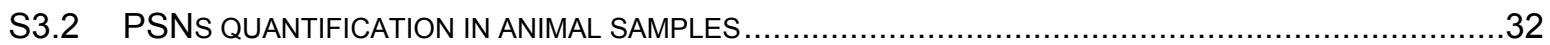




\section{S1 Materials and preliminary measurements}

To avoid any contamination issues and bias linked with the presence of plastic, glass materials were used whenever it was possible. The original suspension of polystyrene nanobeads from Polysciences and all DCVJ solutions were stored in a fridge. By using tinted glassware, aluminum wrapping and storage in a light-blocking compartment, the solutions containing DCVJ were protected from light throughout the experiments.

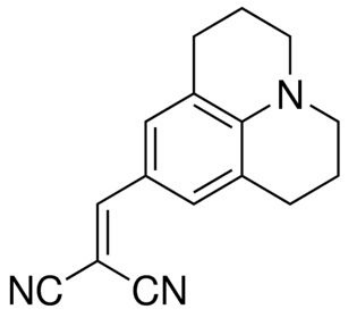

Figure S1. Structure of DCVJ, the fluorescent molecular rotor used in the present work.

\section{S1.1 Preliminary measurements}

Absorption. In order to determine the maximum of absorption of DCVJ in presence and in absence of nanoplastics, absorption spectra were recorded using a UV-vis spectrophotometer (Perkin Elmer, lambda 35). The commercial polystyrene latex suspensions LB1 and LB3 were successively diluted to prepare standard solutions $\left(5,10,20,30,40\right.$ and $50 \mu \mathrm{g} \cdot \mathrm{L}^{-1}$. In an analysis cuvette (Hellma Precision cells made of Quartz suprasil, 100-QS, light path $10 \mathrm{~mm}$ ), $600 \mu \mathrm{L}$ of DCVJ $(40 \mu \mathrm{M}, \mathrm{MeOH})$ were successively added to $2.4 \mathrm{~mL}$ of either $\mathrm{H}_{2} \mathrm{O}$, LB1 standards or LB3 standards (final NPs concentration: $0,4,8,16,24,32,40 \mu \mathrm{g} \cdot \mathrm{L}^{-1}$ ). Using the software UV WinLab explorer, the spectra were monitored from 200 to $700 \mathrm{~nm}$ in $1 \mathrm{~nm}$ increments, a slit width of $1 \mathrm{~nm}$ and a scan speed of $440 \mathrm{~nm} / \mathrm{min}$. In the absence of an internal temperature probe, the room temperature, measured at $21{ }^{\circ} \mathrm{C}$, was recorded. The maximum of absorption was found to be at $468 \mathrm{~nm}$.

Fluorescence. The fluorescence spectra of DCVJ were measured using a fluorescence spectrophotometer (Perkin Elmer, LS55). In a cuvette, $600 \mu \mathrm{L}$ of DCVJ $(40 \mu \mathrm{M}, \mathrm{MeOH})$ were successively added to $2.4 \mathrm{~mL}$ of either $\mathrm{H}_{2} \mathrm{O}$, LB1 standards or LB3 standards (final NPs concentration: $\left.0,4,8,16,24,32,40 \mu \mathrm{g} \cdot \mathrm{L}^{-1}\right)$. Using the $B \mathrm{~L}$ develop software, the spectra were recorded from 400 to $700 \mathrm{~nm}$ in increments of $0.5 \mathrm{~nm}$ and with a scan speed of $1500 \mathrm{~nm} / \mathrm{min}$. In the absence of an internal temperature probe, the temperature of the room, $23{ }^{\circ} \mathrm{C}$, was recorded. Then, DCVJ was first excited at $468 \mathrm{~nm}$, the maximum of absorption obtained in the previous measurement. An excitation wavelength of $450 \mathrm{~nm}$ was then used to match what has been done in literature. ${ }^{1}$ Finally, the excitation was set at $489 \mathrm{~nm}$ to test the excitation peak given by Haidekker and Theodorakis. ${ }^{2}$ Since the expected correlation between the concentration of polystyrene nanobeads and the fluorescence signal was not obtained, different parameters were modulated. The excitation and emission slits were successively set at 10,15 and $20 \mathrm{~nm}$ and the gain of the signal was varied from medium to high. To investigate

\footnotetext{
${ }^{1}$ Gagné, F. Detection of Polystyrene Nanoplastics in Biological Tissues with a Fluorescent Molecular Rotor Probe. J Xenobiotics 2019.

2 Haidekker, M. A.; Theodorakis, E. A. Environment-Sensitive Behavior of Fluorescent Molecular Rotors. Journal of Biological Engineering 2010, 4 (1), 11.
} 
the nature of the emission peak at $468 \mathrm{~nm}$, an $\mathrm{H}_{2} \mathrm{O}$ sample (without DCVJ or NPs) was analyzed. The emission pattern of DCVJ in presence of a higher concentration of nanoplastics, namely $800 \mu \mathrm{g} \cdot \mathrm{L}^{-1}$, was also analyzed. The fluorescence of $8 \mu \mathrm{M}$ DCVJ was also assessed in the presence of glycerol (final concentration of $16,32,48$ and $64 \% \mathrm{w}$ ), a medium known to give measurable DCVJ emission intensity variation as a function of the concentration, ${ }^{3}$ to determine whether the DCVJ stock solution had been degraded.

Dynamic light scattering. To test the hypothesis of NPs aggregation in water, 5 and $50 \mu \mathrm{g} \cdot \mathrm{L}^{-1}$ LB1 samples were analyzed by dynamic light scattering (DLS) (Zetasizer nano series, Nano ZS, Malvern Panalytical). Three and a half months later, aqueous suspensions of PSB49 (100 $\mathrm{mg} \cdot \mathrm{L}^{-1}$ and $\left.1 \mathrm{~g} \cdot \mathrm{L}^{-1}\right)$, LB1 $\left(1 \mathrm{~g} \cdot \mathrm{L}^{-1}\right)$, LB1' $\left(1 \mathrm{mg} \cdot \mathrm{L}^{-1}\right.$ and $\left.1 \mathrm{~g} \cdot \mathrm{L}^{-1}\right)$, LB3 $\left(1 \mathrm{~g} \cdot \mathrm{L}^{-1}\right)$ and LB3' $\left(1 \mathrm{mg} \cdot \mathrm{L}^{-}\right.$ 1 and $\left.1 \mathrm{~g} \cdot \mathrm{L}^{-1}\right)$ were measured to assess their stability throughout the duration of the project.

\footnotetext{
${ }^{3}$ Kung, C. E.; Reed, J. K. Fluorescent Molecular Rotors: A New Class of Probes for Tubulin Structure and Assembly. Biochemistry 1989, 28 (16), 6678-6686.
} 


\section{S2 Method development - PSNs quantification using DCVJ fluorescence}

The first step was to replicate the procedure found in a previous study. ${ }^{4}$ Several tests were then performed to optimize as many parameters as possible. Using NPs solutions of known concentration, the objective was to determine which protocol, including the sample preparation, the microplate reader settings and the data processing, leads to the most accurate quantification of NPs using DCVJ fluorescence.

The Gen5 ${ }^{\mathrm{TM}}$ protocol settings that were studied are described in Table S1.

\begin{tabular}{lll}
\hline Setting & Description & Value \\
\hline$\lambda_{\text {min }}, \lambda_{\text {max }}$ & measured wavelengths & $\lambda_{\text {min }}=480 \mathrm{~nm}, \lambda_{\text {max }}=800 \mathrm{~nm}$ \\
$\lambda_{i}$ & wavelength increment between data points & $10 \mathrm{~nm}$ \\
$\lambda_{\text {excitation }}$ & excitation wavelength & $450 \mathrm{~nm}$, except for test 23 \\
$\mathrm{~T}$ & temperature given by the internal probe & - \\
shake & duration of shaking before analysis & - \\
shake intensity & intensity of shaking before analysis & medium \\
$\mathrm{d}_{\text {start }}$ & delay just after shaking and before measurement & - \\
$\mathrm{d}_{\text {wells }}$ & delay after plate movement (between wells) & - \\
$\mathrm{N}_{\text {meas }}$ & number of measurements per data point & 10 \\
sensitivity & can be fixed or adjusted on a specific well & 100, except for tests 8 and 9 \\
bandwidth & spectral bandpass of the monochromator & $13.5 \mathrm{~nm}$, except for test 24 \\
\hline
\end{tabular}

Table S1. Description of the Gen5 $5^{\mathrm{TM}}$ protocol settings that were studied to optimize the method. No value (-) is indicated when the corresponding parameter was often varied from one test to the next. Concerning the temperature, a value of $25{ }^{\circ} \mathrm{C}$ was selected. However, it was often not possible to stabilize the instrument at that desired value.

\footnotetext{
${ }^{4}$ Gagné, F. Detection of Polystyrene Nanoplastics in Biological Tissues with a Fluorescent Molecular Rotor Probe. J Xenobiotics 2019.
} 


\section{S2.1 Procedure}

Whenever DCVJ was handled during the sample preparation, light exposure was minimized in order to avoid any bias related to the effect of radiations other than the instrument excitation. The microplate to be analyzed was carried inside a closed box from the sampling room to the microplate reader. In addition, to avoid any delay, the device was switched on, the analysis protocol elaborated and loaded before filling the microplate. Once inserted in the instrument, the temperature given by the internal probe was recorded.

After collection from the Gen5 ${ }^{\circledR} 1.11$ software, the raw data were processed using Excel and Matlab. The arithmetic mean and the standard deviation were computed over the four replicates. The relation between DCVJ emission and the concentration of NPs was studied by drawing the fluorescence spectra corresponding to each quadruplicate and by plotting the average fluorescence intensity as a function of NPs concentration for the wavelengths of interest. A regression line was drawn using the least squares method. The slope and linearity of that calibration, as well as the standard deviation of the data points, the limit of quantification and thus the signal over noise (SNR) ratio, were the determining factors to assess the measurement results and decide which tests to perform next.

When needed, statistical tests were performed to compare the results. The null hypothesis ( $\mathrm{h}$ $=0$ ), whereby the results are not significantly different, was tested with a $5 \%$ significance level $(\alpha=0.05)$. Due to the limited number of replicates, it was decided to use the student's t-test. The heteroscedastic variant was chosen.

\section{S2.2 Investigation of existing findings}

In the microplate reader, the plate was shaken for $5 \mathrm{sec}$ and a delay of $5 \mathrm{sec}$ was applied before excitation at $450 \mathrm{~nm}$. The fluorescence spectra were analyzed from 480 to $800 \mathrm{~nm}$ in $10 \mathrm{~nm}$ increments (excitation and emission bandwidth: $13.5 \mathrm{~nm}$; sensitivity: 100; delay after plate movement: $100 \mathrm{msec}$ ). The shaking time was then increased to $10 \mathrm{~min}$ and the delay to $1 \mathrm{~min}$.

Note: The lack of protocol details in Gagné's report 5 impedes the reproducibility of the results. Even in pure water, it was not possible to obtain a workable calibration following its indications. Indeed there are only few indications concerning the instrumental setup. The author indicates the use of a dark 96-well microplate, a 10 minutes mixing step when the fluorescent probe is added to the analyte, an excitation wavelength of $450 \mathrm{~nm}$ and the spectra were recorded between 480 and $800 \mathrm{~nm}$. More details would have been valuable. There is no mention about how the mixing step is done (manually or automatically by the instrument), whether it is performed inside the chamber of the instrument or not. The report does not indicate any resting step or delay between the end of mixing and the start of the analysis. The temperature of the microplate reader inside chamber is not given.

In addition, the concentration of mussel matrix used for the assays in the previous study is not ideally reported. A $20 \%(\mathrm{w} / \mathrm{v})$ is mentioned. However, the weight of the mussels depends on the amount of water of liquid contained in the mussels. There is also no indication whether the mussels were cooked for them to open or they were purchased without the shell. That is why

\footnotetext{
5 Gagné, F. Detection of Polystyrene Nanoplastics in Biological Tissues with a Fluorescent Molecular Rotor Probe. J Xenobiotics 2019. https://doi.org/10.4081/xeno.2019.8147.
} 
it was decided, as mentioned in the section dedicated to PSNs quantification in animal tissues, to freeze-dry the dissected stomach mussels to present a repeatable protocol.

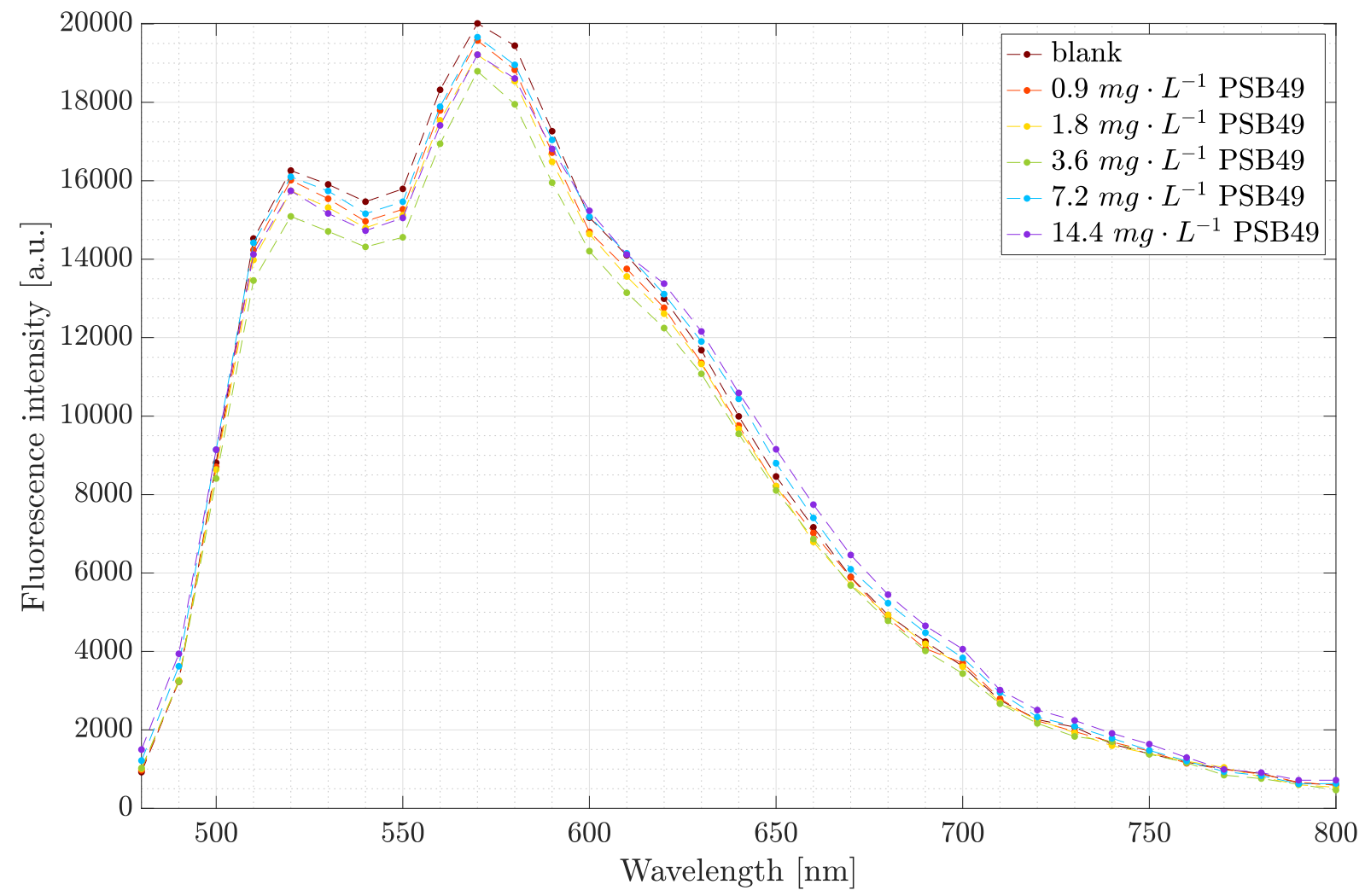

Figure S2: Investigation of existing findings - DCVJ florescence spectrum in presence of increasing concentration of PSB49. The analyses was realized after using Gagné's methodology to prepare the microplate. More precisely, $200 \mu \mathrm{L}$ of $10 \mu \mathrm{M}$ DCVJ, diluted in $\mathrm{H}_{2} \mathrm{O}$ from a $1 \mathrm{mM}$ DCVJ in $\mathrm{MeOH}$ were mixed with $50 \mu \mathrm{L}$ of PSB49. The concentration of DCVJ in the microplate wells was $8 \mu \mathrm{M}$. The same instrumental setup ( $\lambda_{\text {excitation}}$, shaking duration, delay times) as for the test 20 was used (see Table S2) except from the temperature of the inside chamber, which was $26-26.4^{\circ} \mathrm{C}$. 


\section{S2.3 DCVJ fluorescence analysis}

Effect of solvent. In the previous study, DCVJ was diluted in methanol and in water before being mixed with the NPs solutions. ${ }^{34}$ It was decided to record the DCVJ emission spectrum in both media and at different concentrations in order to assess the behavior of the fluorescent probe in those two different solvents. DCVJ $\left(40 \mu \mathrm{M}\right.$ in $\mathrm{MeOH}$, respectively $10 \mu \mathrm{M}$ in $\left.\mathrm{H}_{2} \mathrm{O}\right)$ was added to $\mathrm{MeOH}$, respectively $\mathrm{H}_{2} \mathrm{O}$, to reach a total volume of $250 \mu \mathrm{L}$ and final concentrations of 2, 5, 8 and $10 \mu \mathrm{M}$ of DCVJ in the microplate. The microplate measurement protocol settings are given in the caption of Figure S3. The intensity of fluorescence increases with the concentration of the compound. Whereas one peak at $500 \mathrm{~nm}$ is observed when DCVJ is in methanol, two peaks, with the dominant one situated at $570 \mathrm{~nm}$, are noticed when the rotor is in water. The difference in solvent polarity (water being more polar than methanol) might explain these observations. As DCVJ is hydrophobic, it can be concluded that DCVJ photophysical behavior depends on the solvent.
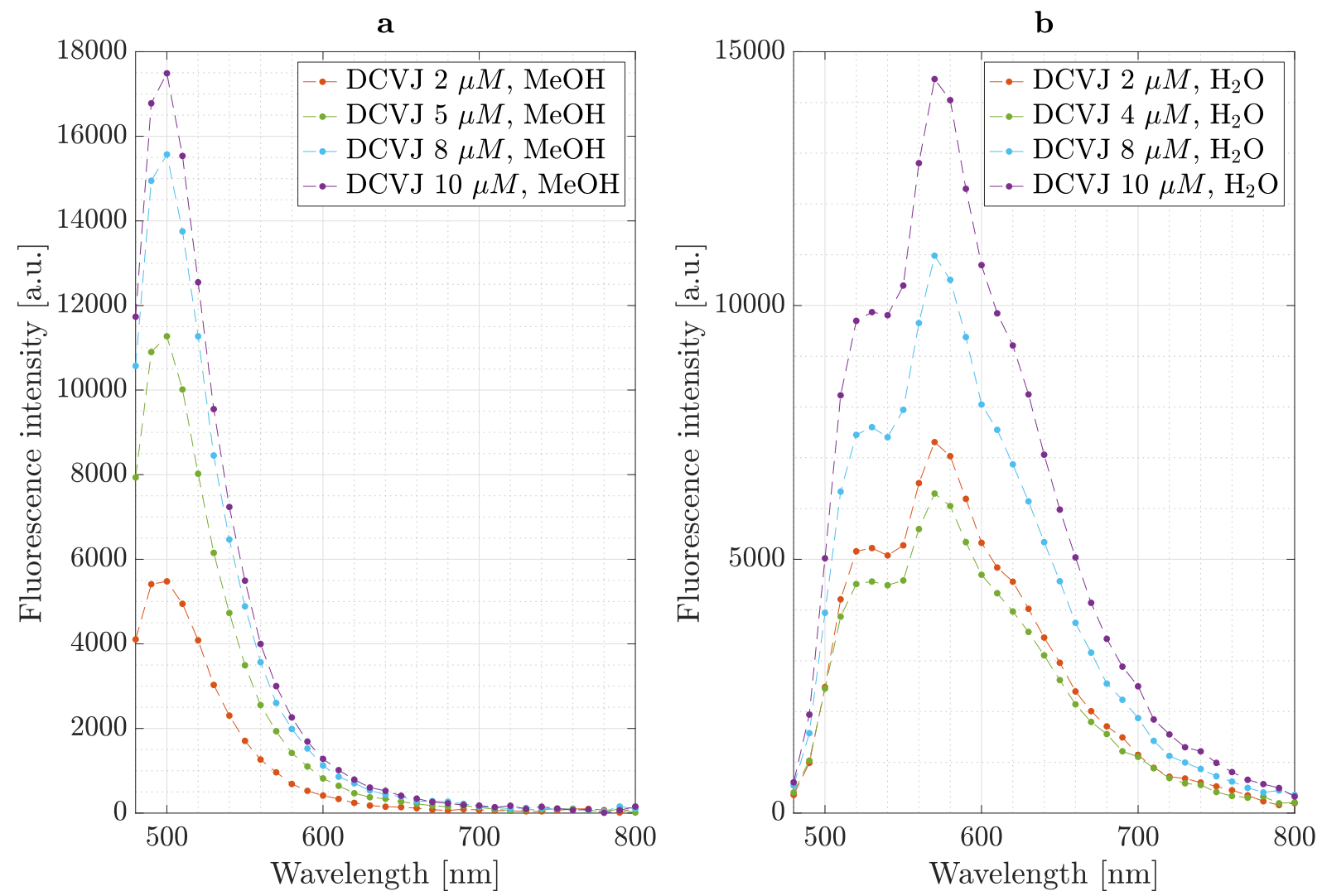

Figure S3. Comparison of DCVJ fluorescence spectrum in methanol (a) and in water (b) at different concentrations. All DCVJ dilutions were prepared from a $1 \mathrm{mM}$ DCVJ stock solution in $\mathrm{MeOH}$. The fluorescence spectra were analyzed from 480 to $800 \mathrm{~nm}$ in $10 \mathrm{~nm}$ increments (excitation wavelength: $450 \mathrm{~nm}$; temperature: $26.6{ }^{\circ} \mathrm{C}$; shake: 5 min; $d_{\text {start }} 1 \mathrm{~min}$; $d_{\text {wells: }}: 100 \mathrm{msec}$; excitation and emission bandwidth: $13.5 \mathrm{~nm}$; sensitivity: 100; delay after plate movement: $100 \mathrm{msec}$ ). 
Effect of pH. The wells of a microplate were filled with $50 \mu \mathrm{L}$ of DCVJ $(40 \mu \mathrm{M}, \mathrm{MeOH})$ mixed with $200 \mu \mathrm{L}$ of either $\mathrm{H}_{2} \mathrm{O}$, buffer Hepes- $\mathrm{NaOH}(10 \mathrm{mM}$, pH 7.4) or commercial buffer solutions (pH 2.00, 4.01, 7.00, 9.21 and 11.00, purchased from METTLER TOLEDO, Switzerland). The microplate measurement protocol settings are given in the caption of Figure S4. The $510 \mathrm{~nm}$ peak of DCVJ fluorescence is not shifted when the $\mathrm{pH}$ of the solution is modified. Concerning the vertical order of the curves, no systematic trend is observed. In the wavelength range that will be used for the NPs detection, namely $600-640 \mathrm{~nm}$, some curves seem to be significantly separated. However, not only the $\mathrm{pH}$ but also different parameters such as the salts contained in the buffer solutions and the microplate reader detector variance might influence the results. This experiment reveals that special care must be taken regarding the $\mathrm{pH}$ and the compounds present in the matrix.

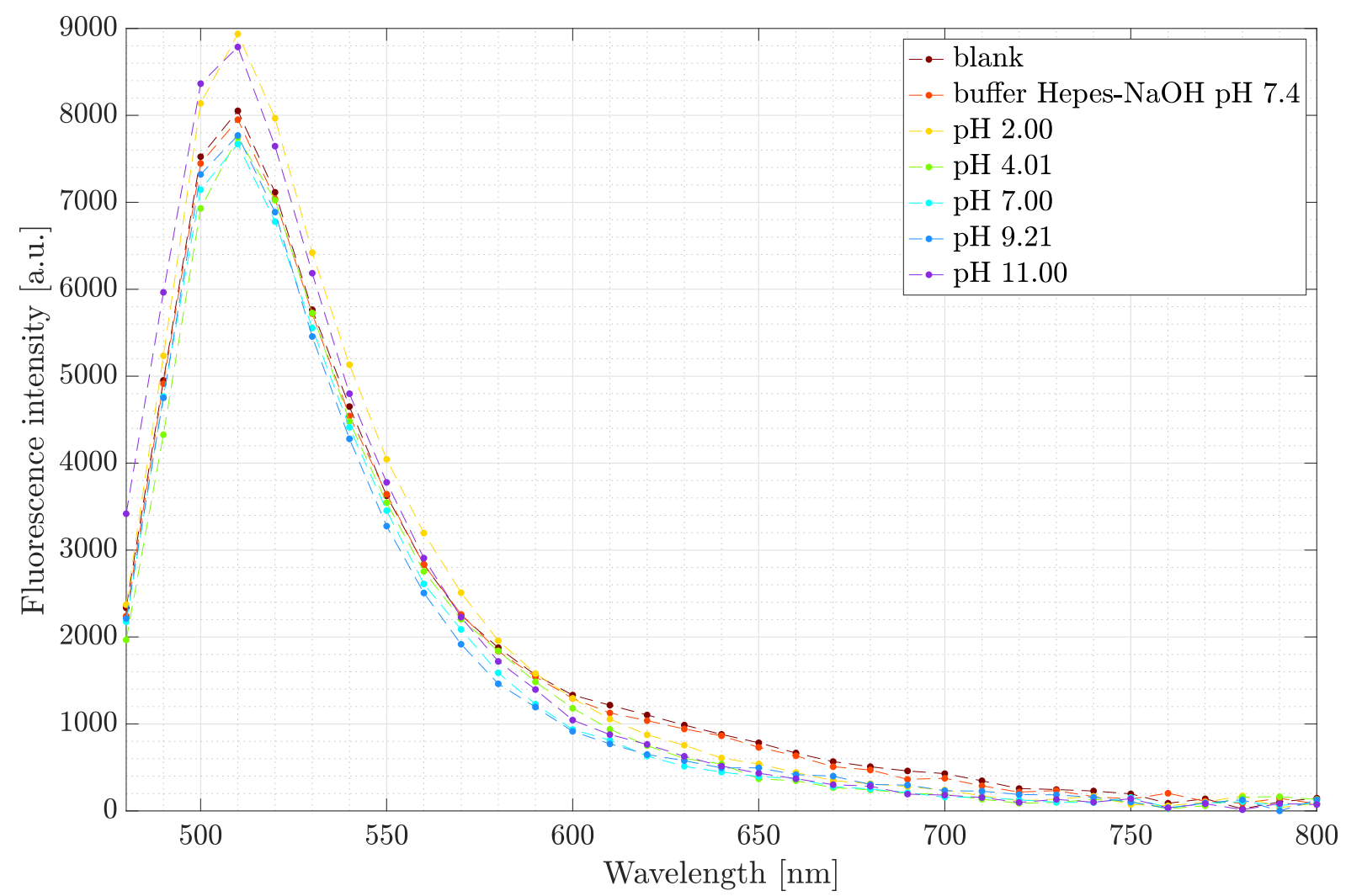

Figure S4. Comparison of DCVJ fluorescence spectrum when subjected to different $\mathrm{pH}$. The fluorescence spectra were analysed from 480 to $800 \mathrm{~nm}$ in $10 \mathrm{~nm}$ increments (excitation wavelength: $450 \mathrm{~nm}$; temperature: 27.7 - 28.3 ${ }^{\circ} \mathrm{C}$; shake: $10 \mathrm{~min}$; $\mathrm{d}_{\text {start }}: 5 \mathrm{~min}$; $\mathrm{d}_{\text {wells }}: 2 \mathrm{sec}$; excitation and emission bandwidth: $13.5 \mathrm{~nm}$; sensitivity: 100; delay after plate movement: $100 \mathrm{msec}$ ). 
Effect of light exposure. A clear glass flask was filled with $5 \mathrm{~mL}$ of DCVJ $(40 \mu \mathrm{M}, \mathrm{MeOH})$ and exposed to UV light using a UV lamp (365 nm). At different time points $(0,1,5,10,20,30$ and $40 \mathrm{~min}$ ), an aliquot was transferred in a tinted glass vial and stored in the dark. The wells of a microplate were then successively filled with $200 \mu \mathrm{L}$ of $\mathrm{H}_{2} \mathrm{O}$ and $50 \mu \mathrm{L}$ of each aliquot. The microplate measurement protocol settings are given in the caption of Figure S5. As illustrated in that figure, the emission spectra of DCVJ after various UV (365 nm) exposure times are close to each other and the peak $(510 \mathrm{~nm})$ is not shifted. The vertical order of the curves is not the same depending on the x-position. At the point of maximum intensity, a greater dispersion between the curves is observed. At $600 \mathrm{~nm}$, all curves seem to converge toward the same yposition. Globally, the fluorescent behavior of DCVJ is not drastically affected by $365 \mathrm{~nm}$ light irradiation. This is especially the case in the $600-640 \mathrm{~nm}$ region, the region chosen for NPs quantification, where the curves are relatively close to each other. However, it is not possible to generalize that statement to the effect of other irradiation wavelengths. For that reason and to avoid any bias, it was decided to protect from light all solutions containing DCVJ during storage and sample preparation.

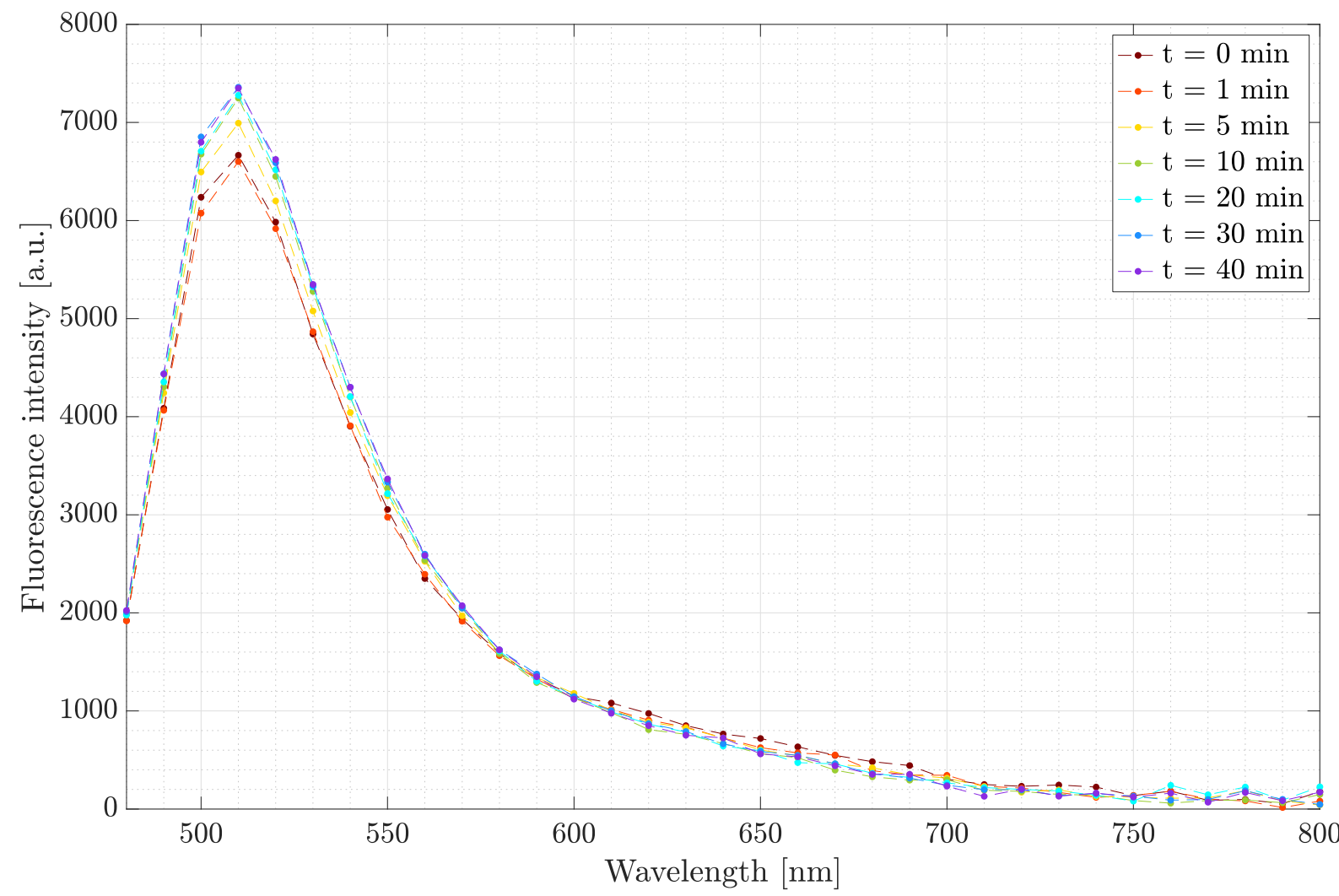

Figure S5. Comparison of DCVJ fluorescence spectrum after different UV light (365 nm) exposure times. The fluorescence spectra were analyzed from 480 to $800 \mathrm{~nm}$ in $10 \mathrm{~nm}$ increments (excitation wavelength: $450 \mathrm{~nm}$; temperature: $30.4-30.8^{\circ} \mathrm{C}$; shake: $10 \mathrm{~min}$; $\mathrm{d}_{\text {start }} 5 \mathrm{~min}$; $\mathrm{d}_{\text {wells }}: 2 \mathrm{sec}$; excitation and emission bandwidth: $13.5 \mathrm{~nm}$; sensitivity: 100; delay after plate movement: $100 \mathrm{msec}$ ). 
S2.4 Optimization of the analytical protocol

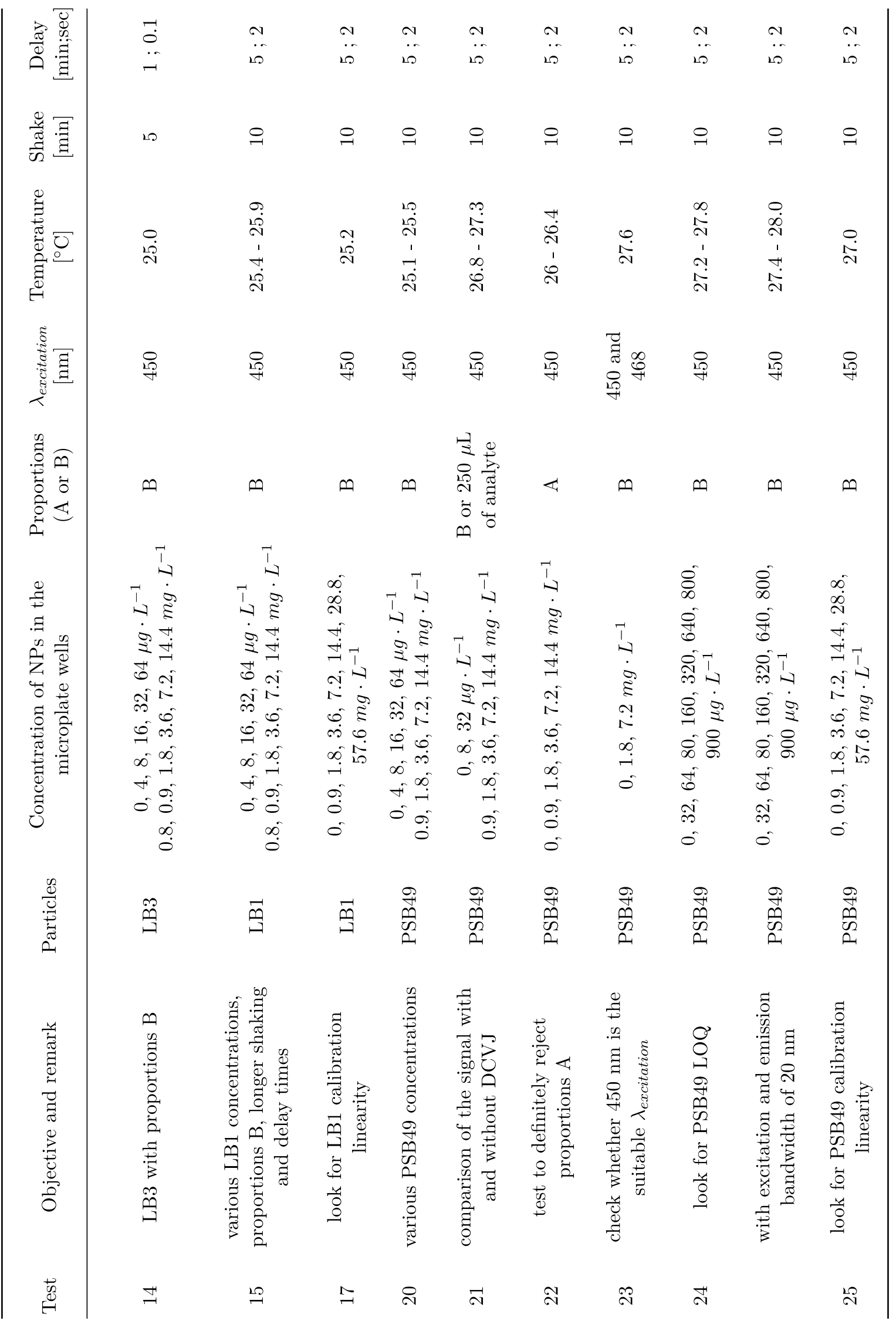


Table S2. Description of the tests realized to develop and optimize the NPs detection method. LB3, LB1, and PSB49 are polystyrene beads of respectively 300,100 and $49 \mathrm{~nm}$ diameter. The proportions column indicates $\mathrm{A}$ if $200 \mu \mathrm{L}$ of DCVJ $(10 \mu \mathrm{M}, \mathrm{H} 2 \mathrm{O})$ is mixed with $50 \mu \mathrm{L}$ of analyte and B if $50 \mu \mathrm{L}$ of DCVJ $(40 \mu \mathrm{M}, \mathrm{MeOH})$ is added to $200 \mu \mathrm{L}$ of analyte. DCVJ concentration was always $8 \mu \mathrm{M}$ in the microplate wells. The zero NPs concentration highlights that a blank was performed. Whereas the first delay value is the equilibrating time just after the shaking step ( $\left.d_{\text {start }}\right)$, the second number represents the delay after the plate movement ( $\mathrm{d}_{\text {wells }}$, between each well of the microplate). Whenever the temperature at the beginning of the microplate shaking step was different from the one at the end of the analysis, the initial and final values are given, separated by a hyphen.
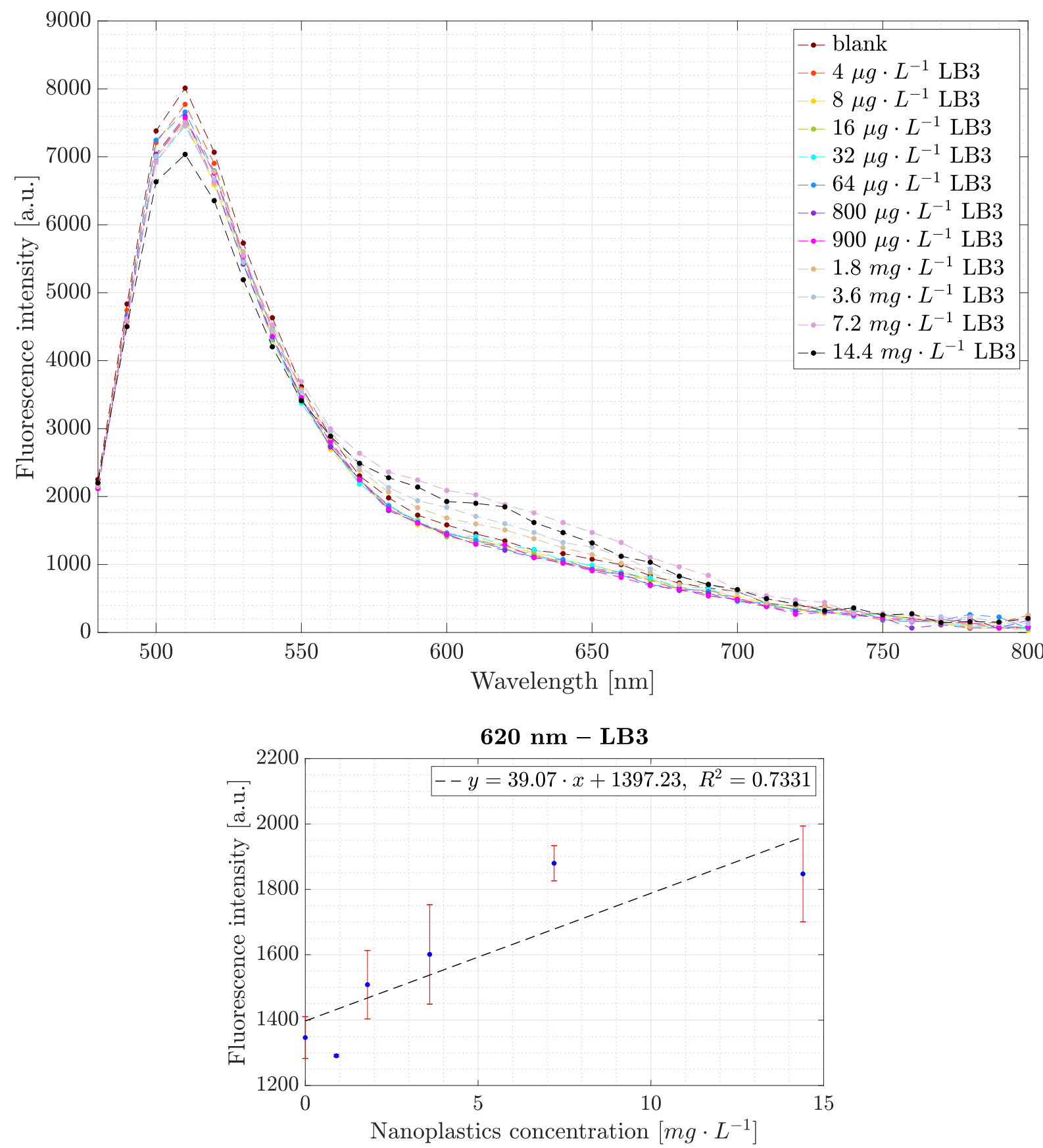

Figure S6. Test 14 - Fluorescence spectra of DCVJ in presence of increasing concentration of LB3 (300 nm PSN). The plot of the signal intensity as a function of LB3 concentration is given at $620 \mathrm{~nm}(0,0.9,1.8,3.6,7.2$ and 14.4 $\left.\mathrm{mg} \cdot \mathrm{L}^{-1}\right)$. 

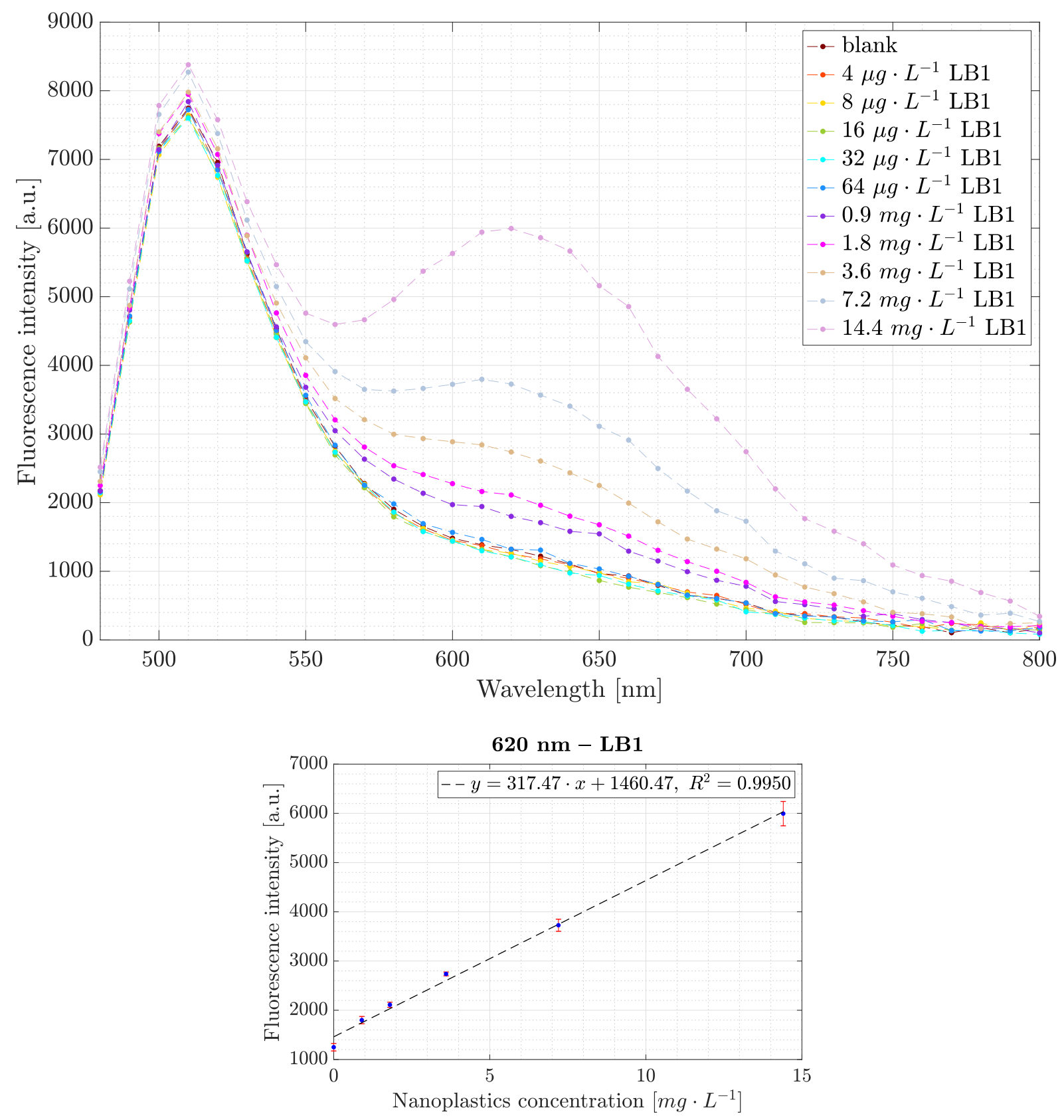

Figure S7. Test 15 - Fluorescence spectra of DCVJ in presence of increasing concentration of LB1 (100 nm PSN). The plot of the signal intensity as a function of LB1 concentration is given at $620 \mathrm{~nm}(0,0.9,1.8,3.6,7.2$ and 14.4 $\left.\mathrm{mg} \cdot \mathrm{L}^{-1}\right)$. 


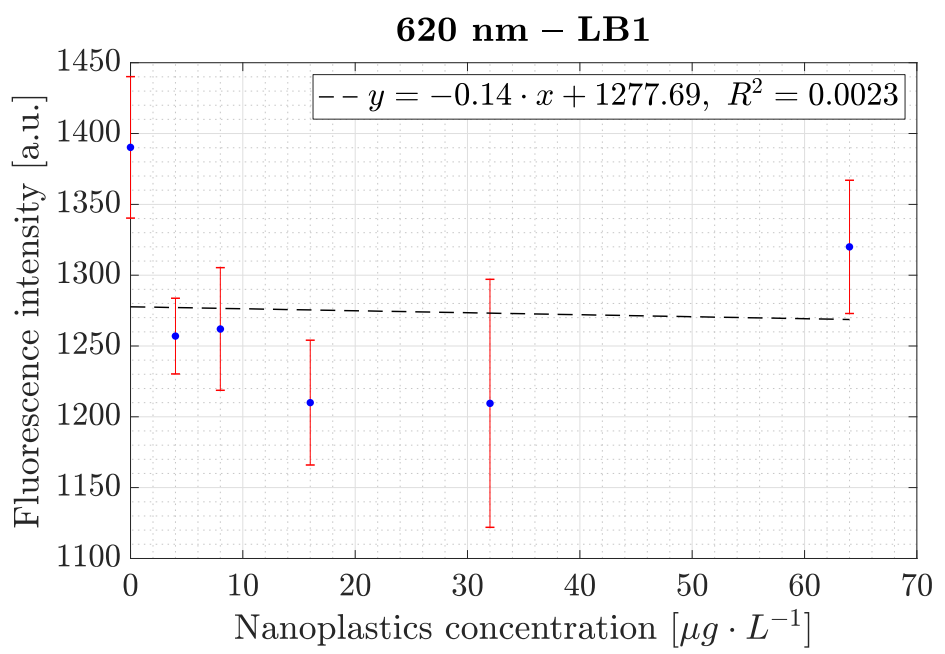

Figure S8. Test 15 - Fluorescence signal intensity of DCVJ as a function of LB1 concentration $(0,4,8,16,32$ and $\left.64 \mu \mathrm{g} \cdot \mathrm{L}^{-1}\right)$. 

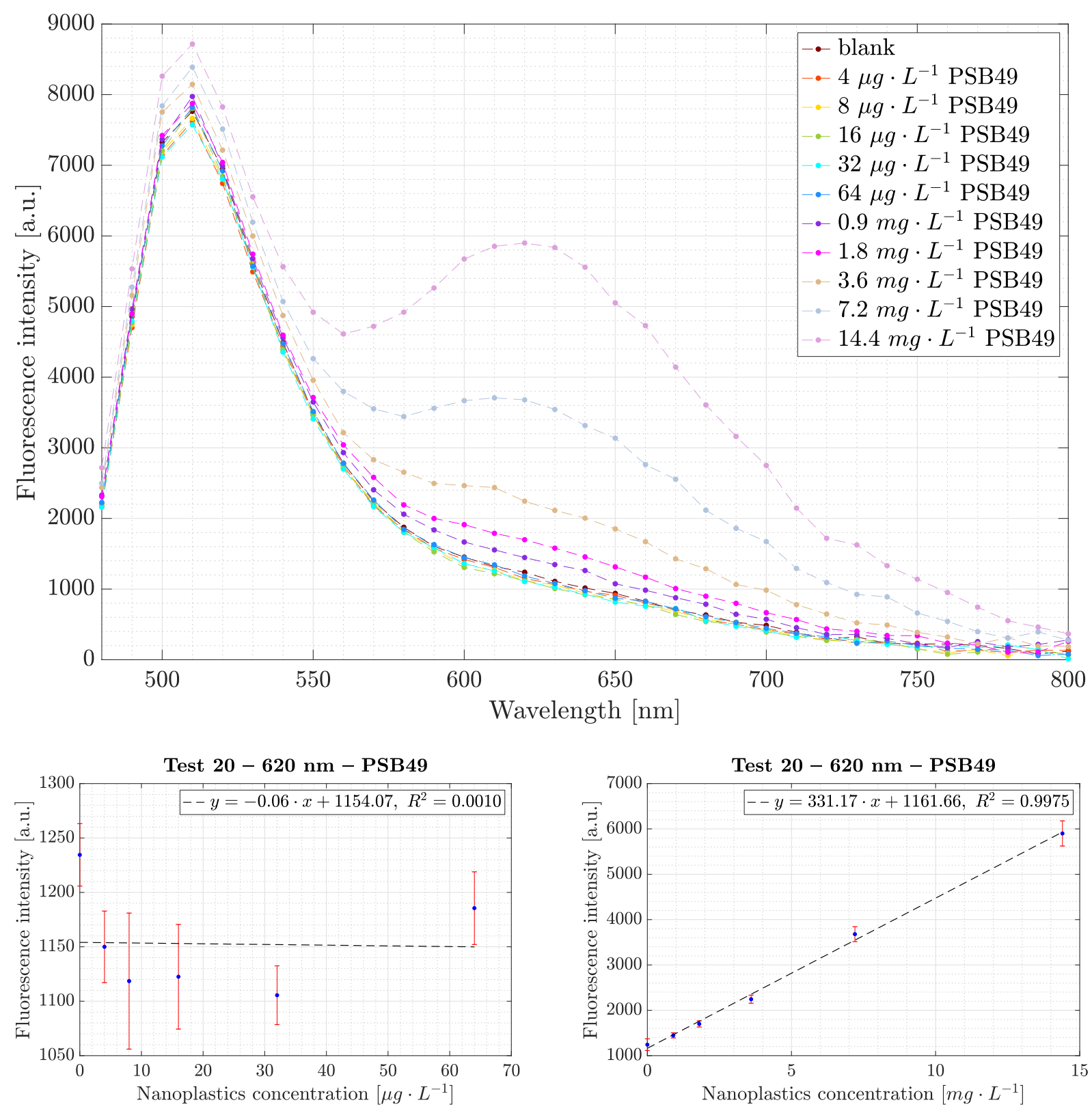

Figure S9. Test 20 - Fluorescence spectra of DCVJ in presence of increasing concentration of PSB49. The plot of the signal intensity as a function of PSB49 concentration is given at $620 \mathrm{~nm}$ (left: $0,4,8,16,32$ and $64 \mu \mathrm{g} \cdot \mathrm{L}^{-1}$; right: $0,0.9,1.8,3.6,7.2$ and $\left.14.4 \mathrm{mg} \cdot \mathrm{L}^{-1}\right)$. 


\section{Note on the excitation wavelength:}

After having obtained satisfying results with $\lambda_{\text {excitation }}=450 \mathrm{~nm}$ (Figure S7 and Figure S9), a test to assess the influence of the excitation wavelength magnitude was conducted. It was decided to use $468 \mathrm{~nm}$, the wavelength at which the absorption of DCVJ is maximum, according to our preliminary measurements (S1.1). Considering the results obtained from two PSB49 concentrations known to be reliable $(1.8 \mathrm{mg} / \mathrm{L}$ and $7.2 \mathrm{mg} / \mathrm{L})$ and comparing the plots when excitation $\lambda_{\text {excitation }}=450 \mathrm{~nm}$ or $468 \mathrm{~nm}$, it was found that $450 \mathrm{~nm}$ is better suited. The signal difference between the curves corresponding to two different nanoplastics concentrations is greater when DCVJ is excited at $450 \mathrm{~nm}$. A greater slope in the plots of the signal as a function of the concentration is obtained.

The following setup was selected to study the influence of the temperature, the magnitude of the NPs specific surface area, the nature of the NPs chemical surface, the matrix and the viscosity on the robustness of the method:

Listing S1. Optimized setup used for the tests realized after optimization of the protocol.

- Particle type: PSB49 (49 nm diameter polystyrene beads), except for the test SA-1 (surface area test, Figure S14), the test CS-1 (chemical surface test, Table S8) and the test NOM-3 (natural organic matter test, Table S9)

- Matrix: $\mathrm{H}_{2} \mathrm{O}$, except for the matrix and viscosity effect tests

- Proportions: B (50 $\mu \mathrm{L}$ of DCVJ at $40 \mu \mathrm{M}$ in $\mathrm{MeOH}$ added to $200 \mu \mathrm{L}$ of analyte)

- DCVJ concentration in the microplate wells: $8 \mu \mathrm{M}$

- $\lambda_{\text {excitation }}: 450 \mathrm{~nm}$

- $\lambda_{\min }, \lambda_{\max }: 480 \mathrm{~nm}, 800 \mathrm{~nm}$

- $\lambda_{\mathrm{i}}: 10 \mathrm{~nm}$

- Shake: $10 \mathrm{~min}$

- Shake intensity: medium

- $\mathrm{d}_{\text {start }} ; \mathrm{d}_{\text {wells }}: 5 \mathrm{~min} ; 2 \mathrm{sec}$

- $\mathrm{N}_{\text {meas }}: 10$

- Sensitivity: 100

- Bandwidth: $13.5 \mathrm{~nm}$ 
Test PSB49 concentration in the microplate wells

T-3 $\quad 0,0.9,1.8,3.6,7.2,14.4,28.8,57.6 \mathrm{mg} \cdot \mathrm{L}^{-1}$
Temperature $\left[{ }^{\circ} \mathrm{C}\right]$

27.0 to 37.0 with $1{ }^{\circ} \mathrm{C}$ increment

The same sequence of quadruplicates with increasing PSB49 concentrations was subsequently analysed with increasing temperature.

Table S3. Overview of the tests realized to evaluate the influence of the temperature on the measurements. The test T-3 at $27^{\circ} \mathrm{C}$ was also used to investigate PSB49 calibration linearity (named test 25 in Table S2).

\begin{tabular}{ccc}
\hline Test & Temperature $\left[{ }^{\circ} \mathbf{C}\right]$ & $\begin{array}{c}\text { Slope of the linear } \\
\text { regression at } \mathbf{6 2 0} \mathbf{~ n m}\end{array}$ \\
\hline T-3 & 27 & $314 \pm 8$ \\
& 28 & $345 \pm 9$ \\
30 & $361 \pm 12$ \\
31 & $361 \pm 7$ \\
32 & $374 \pm 8$ \\
33 & $356 \pm 6$ \\
34 & $349 \pm 11$ \\
35 & $343 \pm 11$ \\
36 & $346 \pm 12$ \\
37 & $339 \pm 13$ \\
& $334 \pm 12$ \\
\hline
\end{tabular}

Table S4. Slopes of the linear regression at $620 \mathrm{~nm}$ fitting the data points from the temperature tests $(0,0.9,1.8$, 3.6, 7.2 and $\left.14.4 \mathrm{mg} \cdot \mathrm{L}^{-1} \mathrm{PSB} 49\right) \mathrm{T}-3$. 


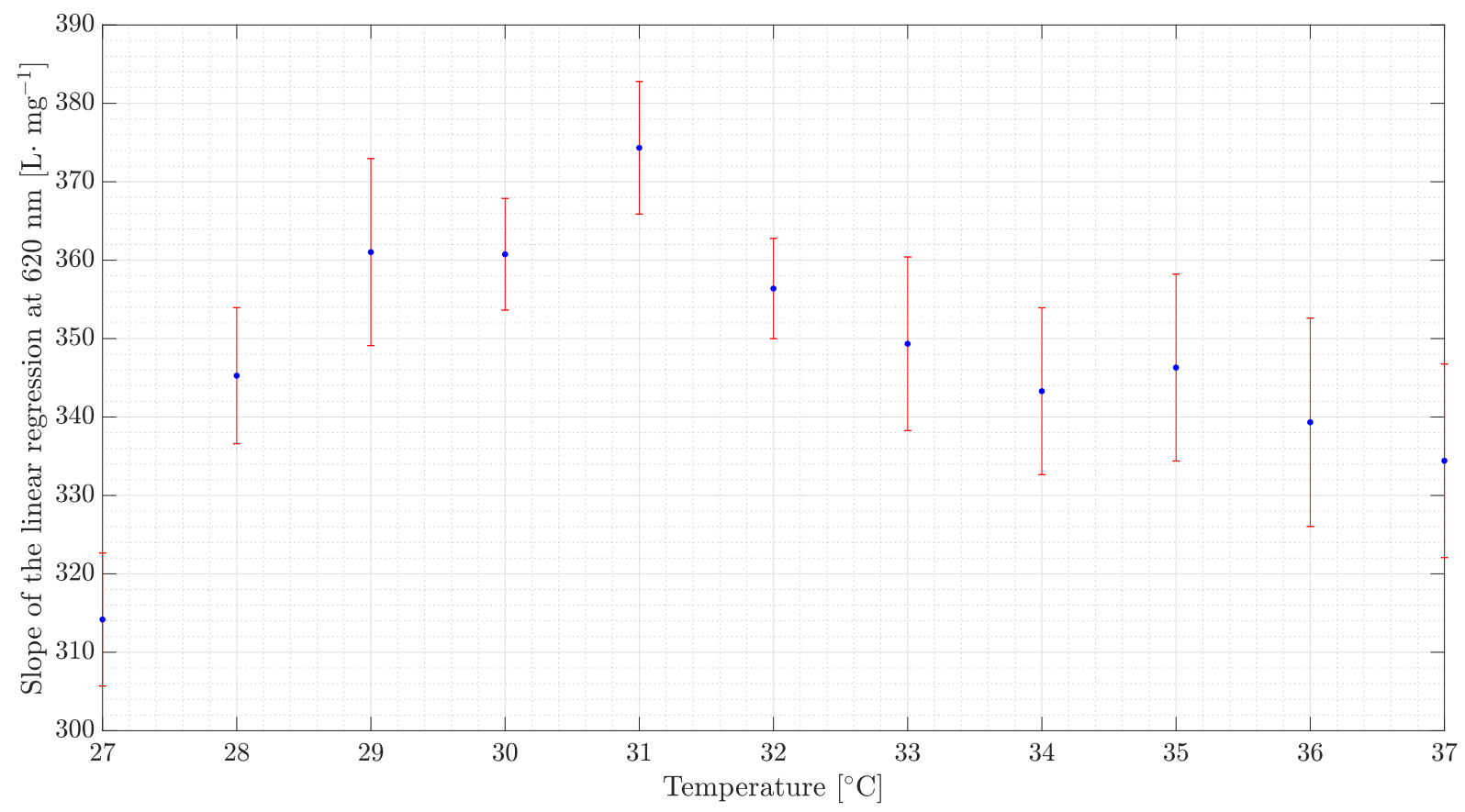

Figure S10. Test T-3 - Slopes of the linear regressions at $620 \mathrm{~nm}$ fitting the data points from the temperature test $\mathrm{T}-3\left(0,0.9,1.8,3.6,7.2\right.$ and $\left.14.4 \mathrm{mg} \cdot \mathrm{L}^{-1} \mathrm{PSB} 49\right)$ as a function of the temperature. Error bars represent the uncertainty on the slope.

Note on the stability of the solutions: The test T-3 also shows that the DCVJ emission is stable over time and so is the dispersion of PSNs mixed with DCVJ. Given the protocol followed to run the experiment (sequential scanning of the same microplate wells), an extended time period passed between the first and last analyses and the spectral intensities remained similar.

\section{S2.6 Theoretical viscosities}

The study of the rheology of a nanofluid - a suspension of nanoparticles in a base fluid - was initiated more than one century ago by Einstein. According to the relation he derived, ${ }^{6}$ the viscosity $\eta$ of a nanofluid increases linearly with the volume fraction $\varphi$ of solid particles:

$$
\eta_{\text {nanofluid }}=\eta_{\text {base fluid }}(1+2.5 \phi) \# \#(1)
$$

The NPs suspensions used in the present study can be identified as nanofluids and the condition of validity of the relation, indicated by Udawattha et al. as $\varphi<0.02$, is verified. ${ }^{7} \eta_{\text {basefluid }}$ can be calculated using the following Vogel-Fulcher-Tammann equation:

$$
\eta=A \exp \left(\frac{B}{T-C}\right) \# \#(2)
$$

\footnotetext{
${ }^{6}$ Einstein, A. Eine Neue Bestimmung Der Moleküldimensionen. Annalen der Physik 1906, 324 (2), $289-306$.

7 Udawattha, D. S.; Narayana, M.; Wijayarathne, U. P. L. Predicting the Effective Viscosity of Nanofluids Based on the Rheology of Suspensions of Solid Particles. Journal of King Saud University - Science 2019, 31 (3), $412-426$.
} 
For $\mathrm{H}_{2} \mathrm{O}$ at $1 \mathrm{~atm}, \mathrm{~A}=0.02939 \mathrm{mP} \cdot \mathrm{s}, \mathrm{B}=507.88 \mathrm{~K}$, and $\mathrm{C}=149.3 \mathrm{~K} \cdot{ }^{8}$ Therefore, $\mathrm{\eta}_{\mathrm{H} 2 \mathrm{O}}=$ $0.89130 \mathrm{mP} \cdot \mathrm{s}$ at $25^{\circ} \mathrm{C}$.

\begin{tabular}{|c|c|c|c|}
\hline Solution & $\begin{array}{c}\text { Temperature } \\
{\left[{ }^{\circ} \mathrm{C}\right]}\end{array}$ & $\begin{array}{l}\text { Viscosity } \\
{[m P \cdot s]}\end{array}$ & $\begin{array}{l}\Delta \text { viscosity with } \\
25^{\circ} \mathrm{C} \mathbf{H}_{2} \mathrm{O} \%\end{array}$ \\
\hline \multirow[t]{2}{*}{$\mathrm{H}_{2} \mathrm{O}$} & 25 & 0.89130 & 0 \\
\hline & 26 & 0.87123 & 2.25 \\
\hline $\begin{array}{c}14.4 m g \cdot L^{-1} \text { PS NPs in } \mathrm{H}_{2} \mathrm{O} \\
\left(\phi=1.37 \cdot 10^{-5}\right)\end{array}$ & 25 & 0.89133 & 0.00343 \\
\hline glycerol $5 \% \mathrm{w}$ in water & 25 & 1.0072 & 13.00 \\
\hline glycerol $10 \% \mathrm{w}$ in water & 25 & 1.1456 & 28.53 \\
\hline
\end{tabular}

Table S5. Comparison of the viscosity of $\mathrm{H}_{2} \mathrm{O}$ at $26{ }^{\circ} \mathrm{C}, 14.4 \mathrm{mg} \cdot \mathrm{L}^{-1} \mathrm{PS}$ beads solution at $25^{\circ} \mathrm{C}$ and glycerol $(5$ and $10 \% \mathrm{w}$ in water) at $25{ }^{\circ} \mathrm{C}$ with $\mathrm{H}_{2} \mathrm{O}$ at $25^{\circ} \mathrm{C}$. Calculations are made using equation (2) for $\mathrm{H}_{2} \mathrm{O}$ and (1) for NPs suspension, with a pressure of $1 \mathrm{~atm}$. The glycerol viscosity was calculated using the equation from Cheng. ${ }^{49}$

\section{S2.7 Influence of the addition of glycerol to PSN}

Test NPs and glycerol concentrations in the microplate wells Temperature $\left[{ }^{\circ} \mathrm{C}\right]$

GLY-1

no particles

$0,5,10,20 \%$ w glycerol

$25.0-25.1$

GLY-2

0, 0.9, 1.8, 3.6, 7.2, $14.4 \mathrm{mg} \cdot \mathrm{L}^{-1} \mathrm{PSB} 49$;

$5 \% \mathrm{w}$ glycerol or $\mathrm{H}_{2} \mathrm{O}$

GLY-3

0, 0.9, 1.8, 3.6, 7.2, $14.4 \mathrm{mg} \cdot \mathrm{L}^{-1} \mathrm{PSB} 49$;

$10 \%$ w glycerol or $\mathrm{H}_{2} \mathrm{O}$

Table S6. Overview of the tests realized to evaluate the influence of the viscosity of the media on the fluorescence of DCVJ in absence and in presence of PSNs.

${ }^{8}$ Viswanath, D. S.; Ghosh, T.; Prasad, D. H. L.; Dutt, N. V. K.; Rani, K. Y. Viscosity of Liquids: Theory, Estimation, Experiment, and Data; Springer Netherlands, 2007. 


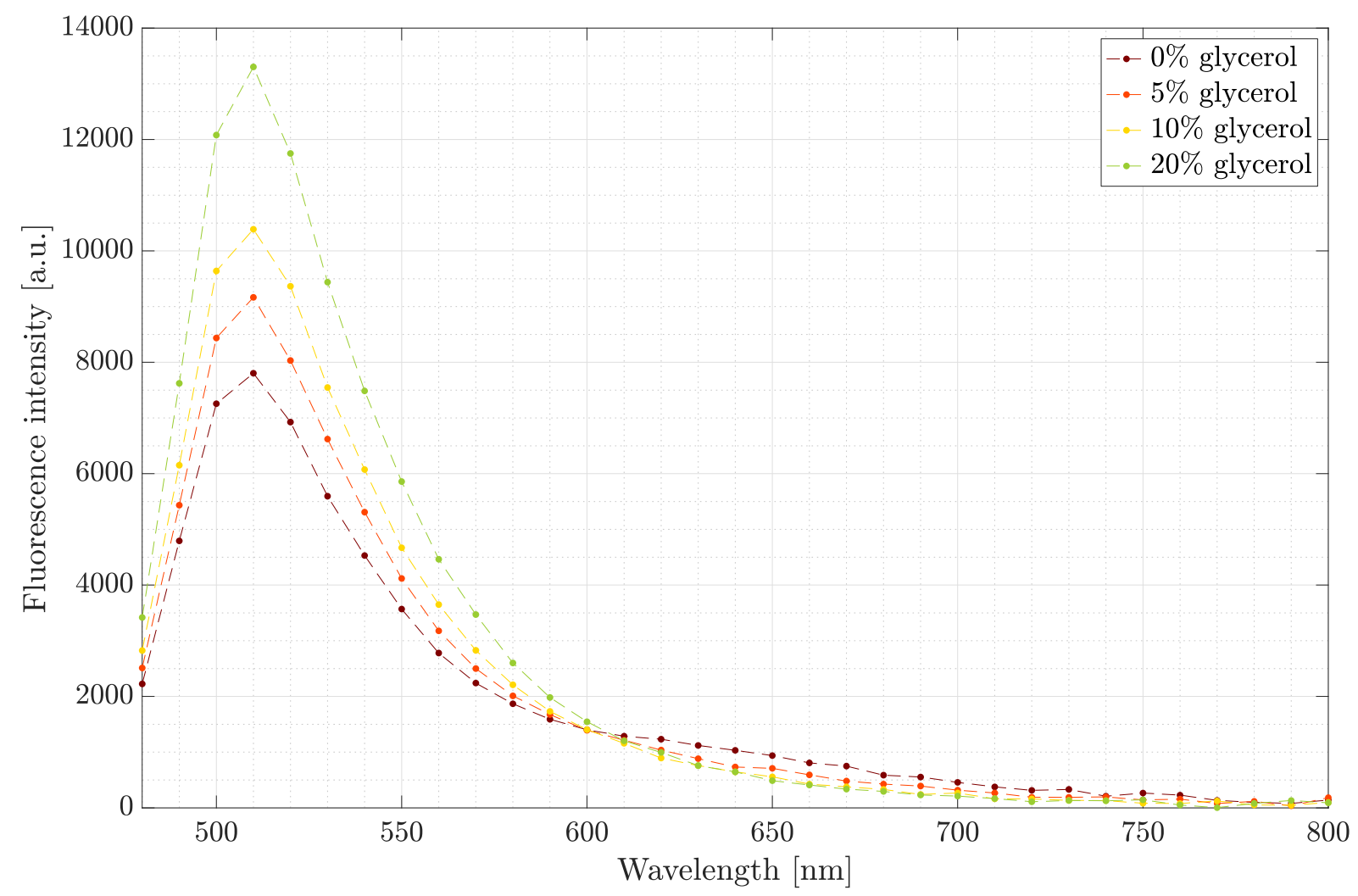

Figure S11. Test GLY-1 - Fluorescence spectra of DCVJ in presence of increasing concentration of glycerol.

By increasing the concentration of glycerol in the media, the $620 \mathrm{~nm}$ fluorescent peak disappears (Figure S12 and Figure S13). As expected, the slope of the linear regression at $620 \mathrm{~nm}$ decreases with the increase in glycerol content in the matrix.

According to the statistical t-test, at equal PSB49 concentration $(0,0.9,1.8,3.6,7.2$ and 14.4 $\mathrm{mg} \cdot \mathrm{L}^{-1} \mathrm{PSB} 49$ ), the signal at $620 \mathrm{~nm}$ arising from the sample in glycerol (either $5 \% \mathrm{w}$ or $20 \% \mathrm{w}$ ) or in $\mathrm{H}_{2} \mathrm{O}$ are significantly different ( $p<0.010$ for GLY-2, $\mathrm{p}<0.004$ for GLY-3).

At equal glycerol concentration, the visual comparison of the spectra associated to two adjacent PSB49 concentration ( 0 and $0.9 \mathrm{mg} \cdot \mathrm{L}^{-1}, 0.9$ and $\left.1.8 \mathrm{mg} \cdot \mathrm{L}^{-1}, \ldots\right)$ in the same glycerol matrix suggests that the data are not distinguishable at $620 \mathrm{~nm}$ and low PSB49 concentration. However, except the 0 and $0.9 \mathrm{mg} \cdot \mathrm{L}^{-1}$ PSB49 data in $10 \%$ glycerol $(p=0.147)$, all other neighboring data are significantly different ( $p<0.033$ for GLY-2, $p \leq 0.023$ for GLY-3).

Further tests could be conducted with higher glycerol concentration to assess the threshold from which viscosity effect dominates the hydrophobic interaction between DCVJ and the plastic beads, thus impeding NPs quantification. 

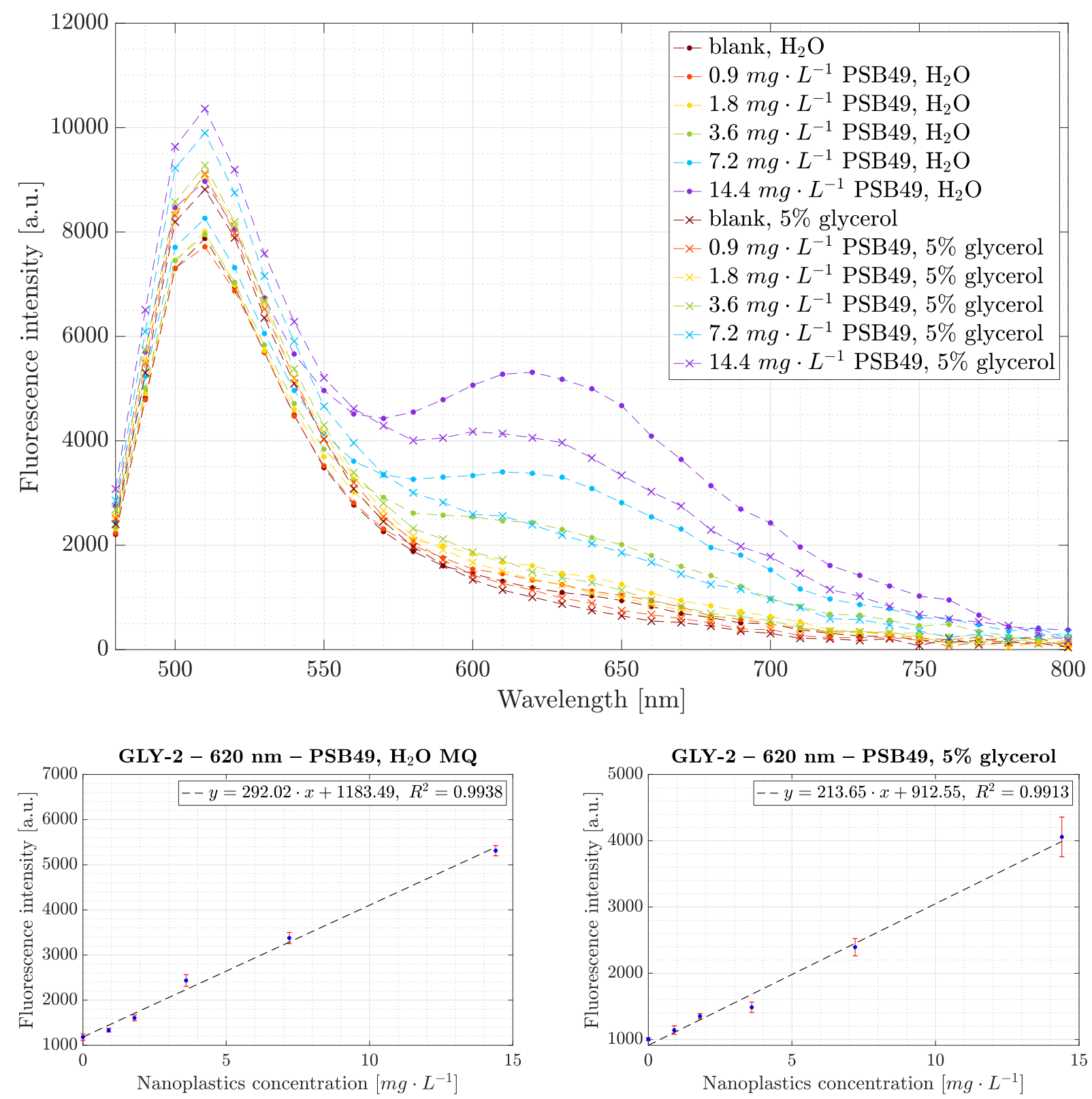

Figure S12. Test GLY-2 - Fluorescence spectra associated to DCVJ in presence of PSB49 $(0.9,1.8,3.6,7.2$ and $14.4 \mathrm{mg} \cdot \mathrm{L}^{-1}$ ) and $5 \% \mathrm{w}$ of glycerol (crosses) or $\mathrm{H}_{2} \mathrm{O}$ (full circles). The blank contains DCVJ $(8 \mu \mathrm{M})$ and either glycerol or $\mathrm{H}_{2} \mathrm{O}$ but no PSB49. The plots of the signal intensity as a function of PSB49 concentration (in either $\mathrm{H}_{2} \mathrm{O}$ or $5 \%$ w glycerol) at $620 \mathrm{~nm}$ are also given and include the linear regression curve fitting the data. 

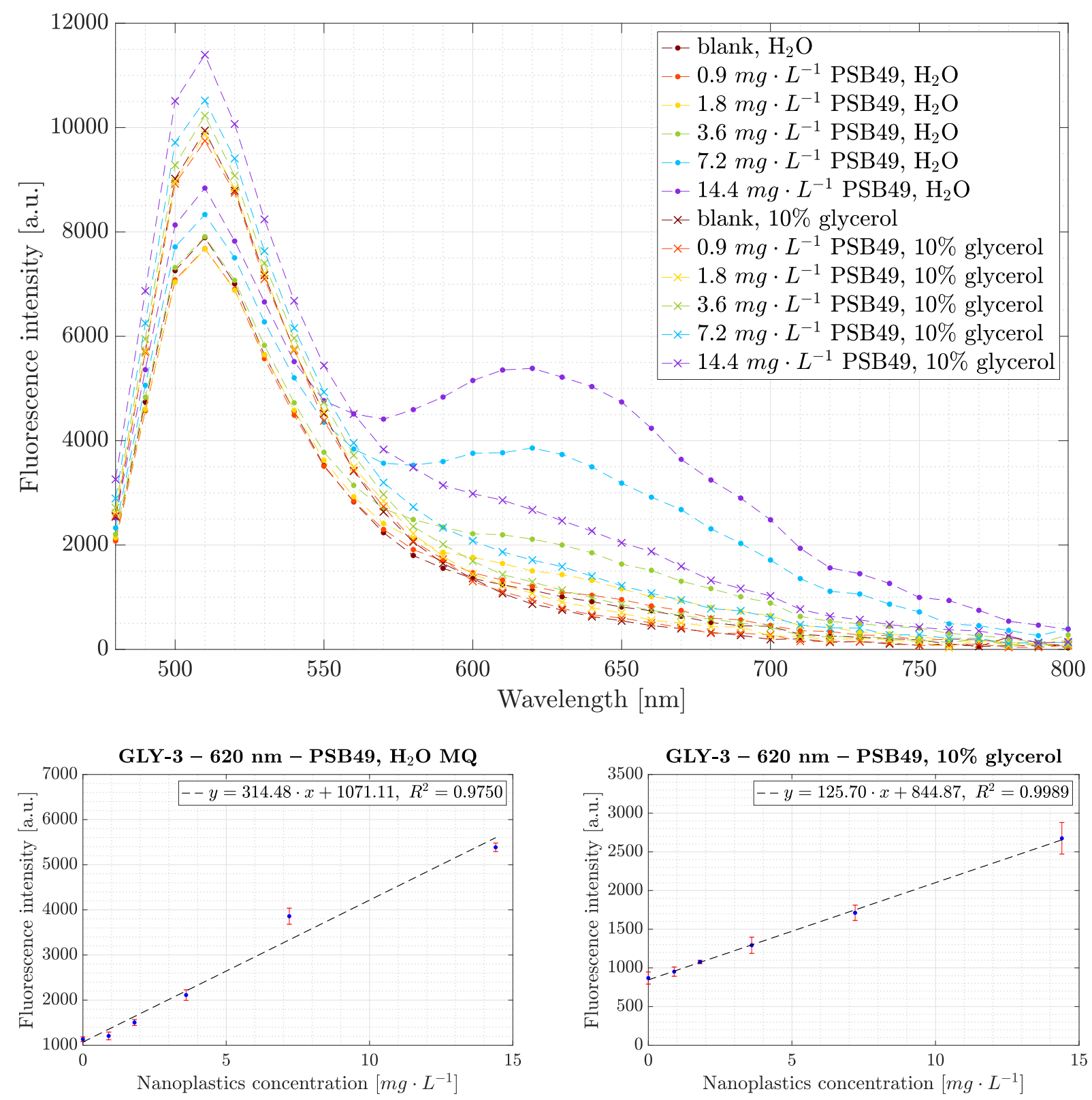

Figure S13. Test GLY-3 - Fluorescence spectra associated to DCVJ in presence of PSB49 $(0.9,1.8,3.6,7.2$ and $14.4 \mathrm{mg} \cdot \mathrm{L}^{-1}$ ) and $10 \% \mathrm{w}$ of glycerol (crosses) or $\mathrm{H}_{2} \mathrm{O}$ (full circles). The blank contains DCVJ $(8 \mu \mathrm{M})$ and either glycerol or $\mathrm{H}_{2} \mathrm{O}$ but no PSB49. The plots of the signal intensity as a function of PSB49 concentration (in either $\mathrm{H}_{2} \mathrm{O}$ or $10 \% \mathrm{w}$ glycerol) at $620 \mathrm{~nm}$ are also given and include the linear regression curve fitting the data. 


\begin{tabular}{cccc}
\hline Test & $\begin{array}{c}\text { Glycerol percentage in the } \\
\text { microplate wells [\%w] }\end{array}$ & $\begin{array}{c}\text { Slope of the linear } \\
\text { regression at } \mathbf{6 2 0} \mathbf{~ n m}\end{array}$ & $\mathrm{R}^{2}$ \\
\hline \multirow{2}{*}{ GLY-2 } & 0 & $292 \pm 12$ & 0.9938 \\
& 5 & $214 \pm 10$ & 0.9913 \\
GLY-3 & 0 & $314 \pm 25$ & 0.9750 \\
& 10 & $126 \pm 2$ & 0.9989 \\
\hline
\end{tabular}

Table S7. Slope of the linear regression at $620 \mathrm{~nm}$ fitting the data points from the viscosity tests GLY-2 and GLY$3\left(0,0.9,1.8,3.6,7.2\right.$ and $\left.14.4 \mathrm{mg} \cdot \mathrm{L}^{-1} \mathrm{PSB} 49\right)$.

\section{S2.8 Surface area vs. diameter}

Based on the size of the particles, the suitable dilutions of PSB49, LB1 and LB3 were prepared to obtain standards solutions of $988,1977,3954,7907$ and $15815 \mathrm{~cm}^{2} \cdot \mathrm{L}^{-1}$ for each of the three different particles. The experiment allows to compare DCVJ's fluorescence response in presence of different beads size at equal surface area concentration.

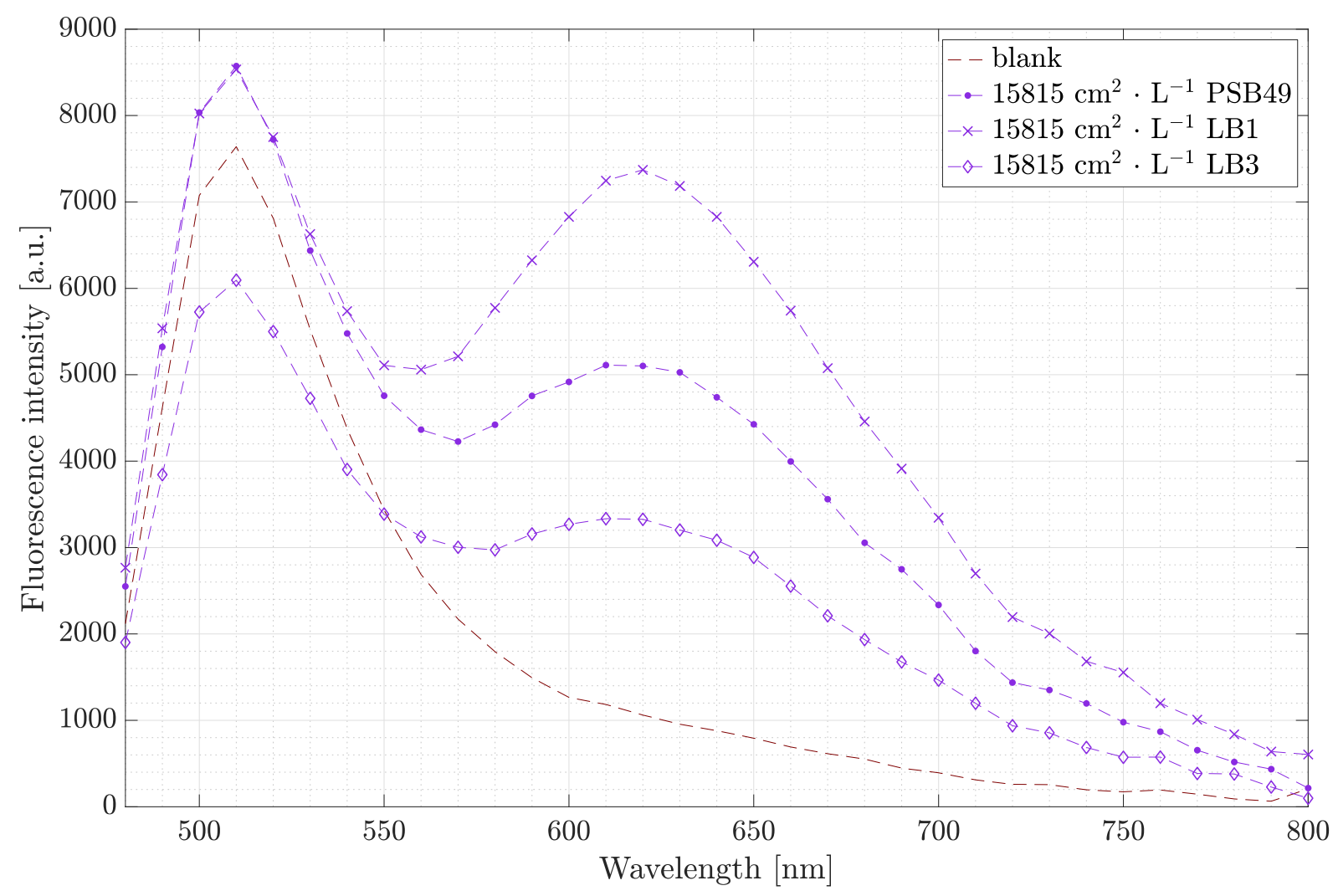

Figure S14. Test SA-1 - Fluorescence spectra of DCVJ in presence of either PSB49 (full circles), LB1 (crosses) or LB3 (empty diamonds) at equal surface area concentration. The surface area is calculated by assuming the beads are perfectly spherical and using the diameter given by the manufacturer. Roughness is neglected. The value is obtained by multiplying the surface area of one bead by the number of beads per liter. The temperature of the inside chamber of the microplate reader varied from 26.4 to $26.9{ }^{\circ} \mathrm{C}$ during the experiment. At any surface area concentration $\left(988,1977,3954,7907\right.$ and $\left.15815 \mathrm{~cm}^{2} \cdot \mathrm{L}^{-1}\right)$, the most intense signal is associated with LB1, the one associated with PSB49 is found in the middle and the least intense signal is related to LB3. For greater clarity, only the spectra associated with $15815 \mathrm{~cm}^{2} \cdot \mathrm{L}^{-1}$ surface area concentration are shown. 


\section{S2.9 Influence of the nanoplastics functionalization}

Test NPs concentration in the microplate wells

Temperature $\left[{ }^{\circ} \mathbf{C}\right]$

CS-1 $0,0.9,1.8,3.6,7.2,14.4 \mathrm{mg} \cdot \mathrm{L}^{-1}$ for PSB49 and PSB49coo

$25.6-26.3$

Table S8. Measurement performed to compare functionalized (49 $\mathrm{nm}$ PS beads) and non-functionalized (carboxyl coated $49 \mathrm{~nm}$ PS beads) PSNs. To allow the best comparison between both types of PSNs, PSB49 and PSB49coo were sampled in the same microplate and analyzed during the same measurement.

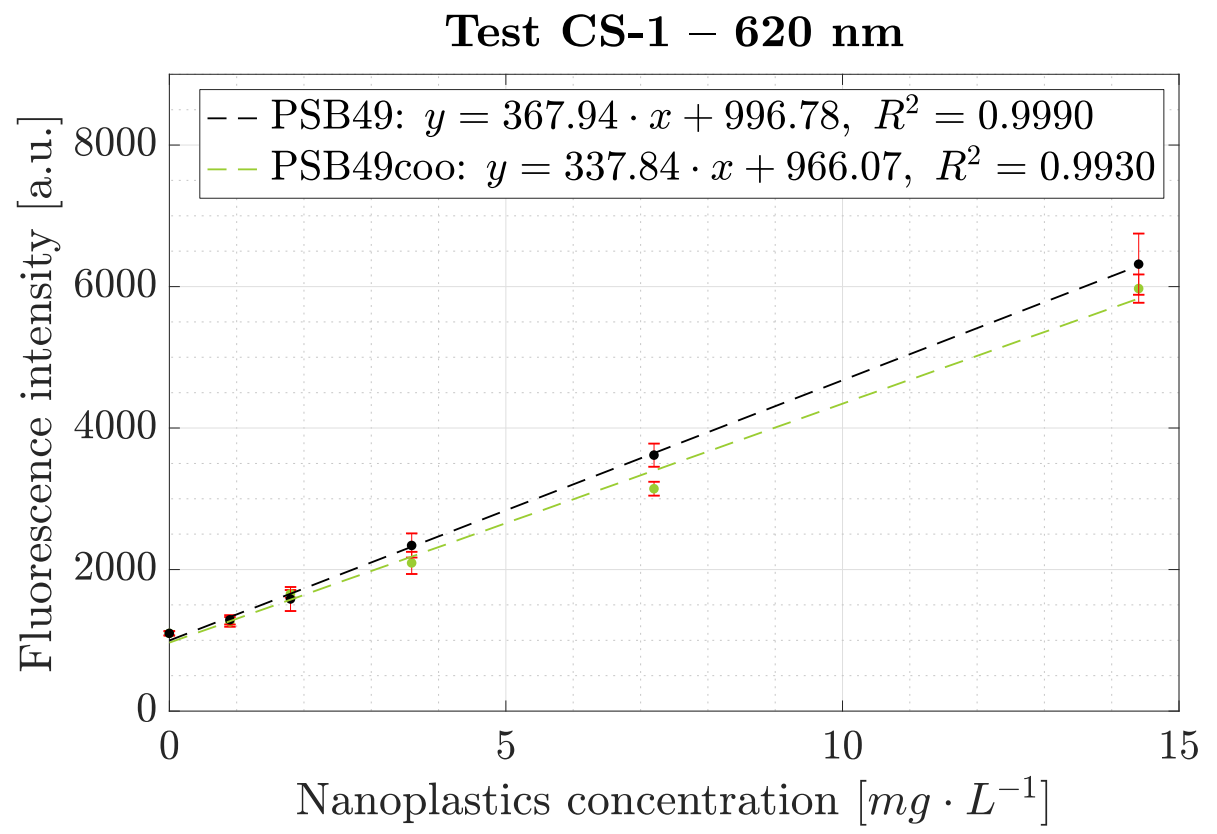

Figure S15. Test CS-1 - Fluorescence signal intensity of DCVJ in presence of either PSB49 (black) or PSB49coo (green) as a function of the bead's concentration. A linear regression curve for both particles is included $(0,0.9$, $1.8,3.6,7.2$ and $\left.14.4 \mathrm{mg} \cdot \mathrm{L}^{-1}, 25.6-26.3^{\circ} \mathrm{C}\right)$. 
S2.10PSN quantification in water and influence of the natural organic matter

\section{Linearity and LOD/LOQ.}
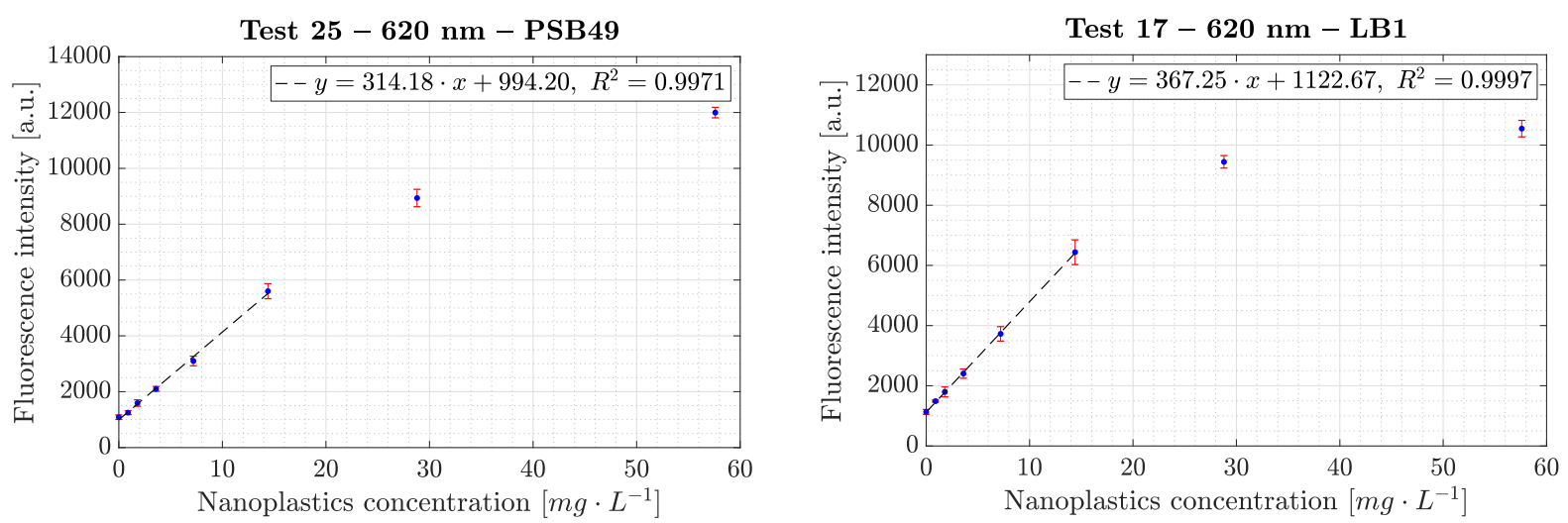

Figure S16. Fluorescence spectra of DCVJ in presence of either PSB49 or LB1 at the concentration used for the calibration $\left(0,0.9,1.8,3.6,7.2,14.4 \mathrm{mg} \cdot \mathrm{L}^{-1}\right)$ and higher $\left(28\right.$ and $\left.57.6 \mathrm{mg} \cdot \mathrm{L}^{-1}\right)$. The linear regression is done over the concentration range going from 0 to $14.4 \mathrm{mg} \cdot \mathrm{L}^{-1}$.

\section{Influence of the NOM.}

Test NPs and matrix concentration in the microplate wells Temperature $\left[{ }^{\circ} \mathrm{C}\right]$

\begin{tabular}{cc}
\hline no particles & $29.3-29.5$ \\
NOM-1 & $2,10,50 \mathrm{mg} \cdot L^{-1}$ NOM without DCVJ \\
$1.6 \mathrm{mg} \cdot L^{-1} \mathrm{NOM}$ with DCVJ &
\end{tabular}

For this NOM-1 test, three sequences of quadruplicates with increasing NOM concentration were prepared in the microplate.

NOM-2 PSB49: $0,0.9,1.8,3.6,7.2,14.4 \mathrm{mg} \cdot \mathrm{L}^{-1} ; \quad \mathrm{NOM}: 1.6 \mathrm{mg} \cdot \mathrm{L}^{-1}$

NOM-3 LB1': $0,0.9,1.8,3.6,7.2,14.4 \mathrm{mg} \cdot \mathrm{L}^{-1} ; \quad \mathrm{NOM}: 1.6 \mathrm{mg} \cdot \mathrm{L}^{-1}$

28.1

Table S9. Overview of the tests realized to evaluate the influence of the NOM on the quality of the calibration. 


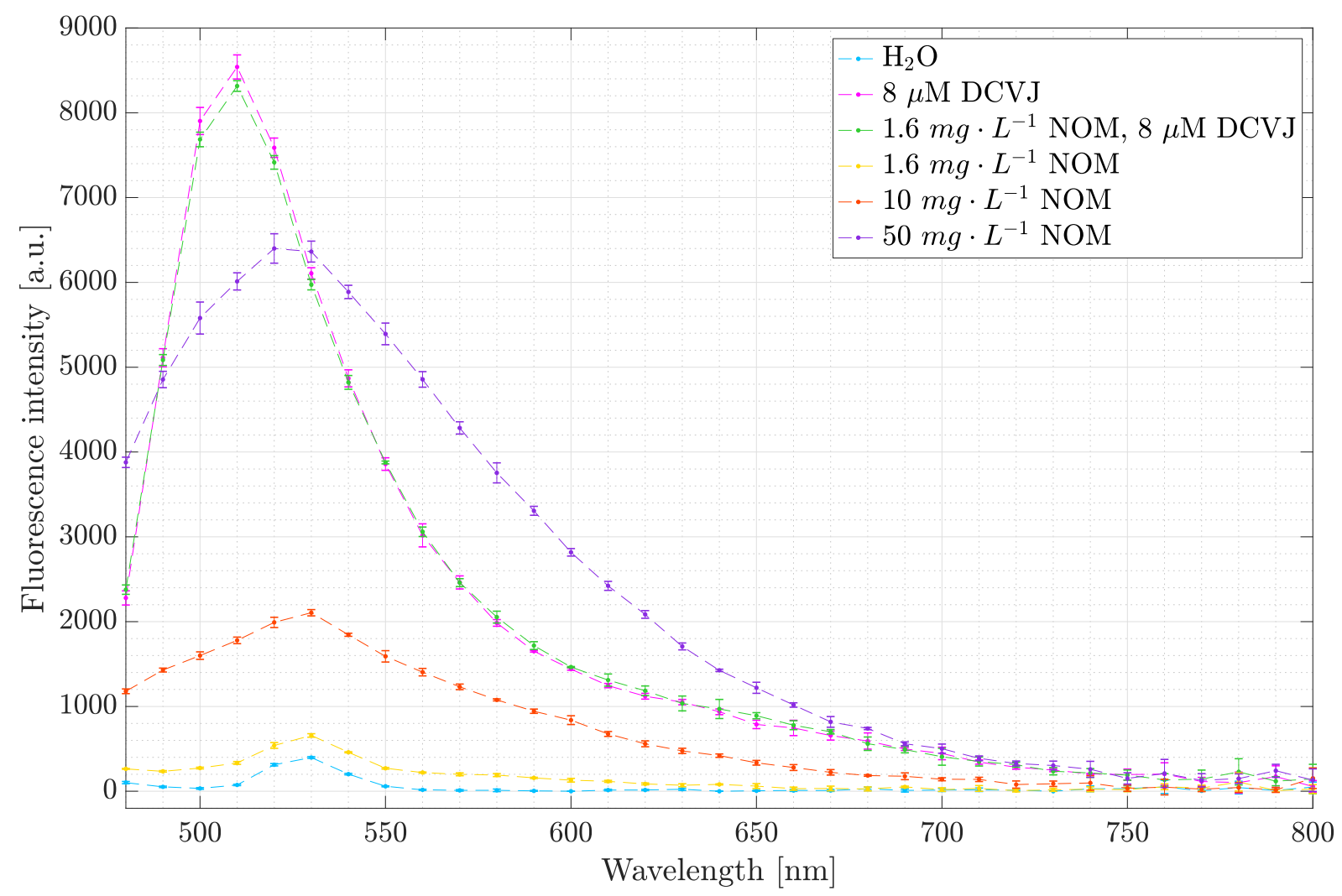

Figure S17. Test NOM-1 - Fluorescence spectra of NOM at different concentrations with and without DCVJ. The spectra of DCVJ (8 $\left.\mu \mathrm{M}, 1: 4 \mathrm{MeOH}: \mathrm{H}_{2} \mathrm{O} M Q\right)$ as well as $\mathrm{H}_{2} \mathrm{O} M Q$ is included for the comparison. 

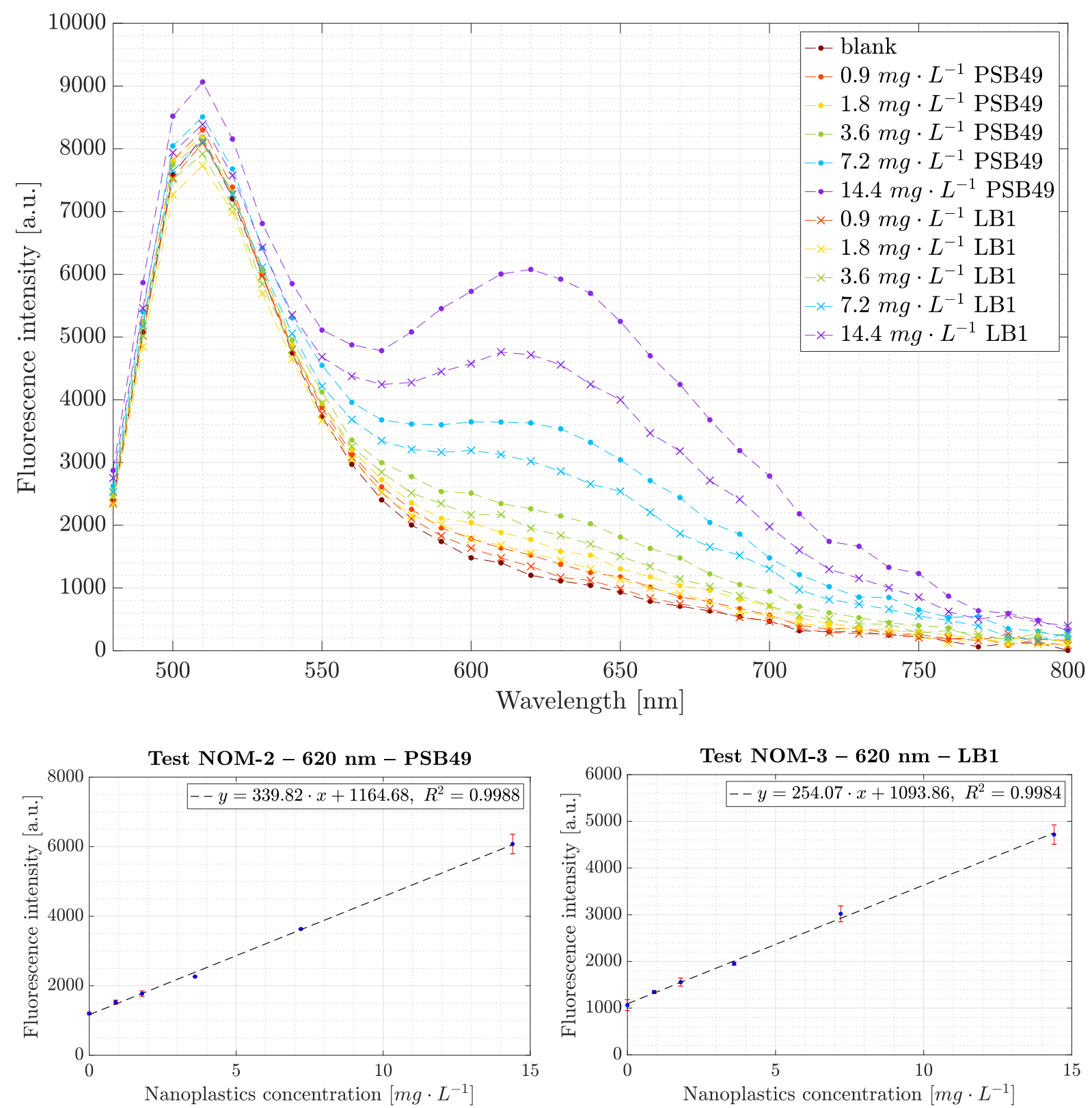

Figure S18. Test NOM-2 and NOM-3 - Fluorescence spectra of DCVJ in presence of NOM $\left(1.6 \mathrm{mg} \cdot \mathrm{L}^{-1}\right)$ and either PSB49 (full circles) or LB1 (crosses). The blank being DCVJ $(8 \mu \mathrm{M})$ in NOM $\left(1.6 \mathrm{mg} \cdot \mathrm{L}^{-1}\right)$. The plots of the signal intensity as a function of either PSB49 or LB1 concentration are also given and include the linear regression curve fitting the data. 


\section{S3 Method application - PSNs quantification in biological samples}

\section{S3.1 PSNs quantification in vegetal samples}

50 and $200 \mathrm{mg} \cdot \mathrm{L}^{-1}$ stock radish matrix were prepared by precisely weighing the sprouts in a graduated flask which was then filled with $\mathrm{H}_{2} \mathrm{O} M Q$. After 15 min in an ultrasonic bath, the liquid was filtered on a $0.45 \mu \mathrm{m}$ PTFE filter. PSB49 standards solutions $\left(1.125,2.25,4.5,9,18 \mathrm{mg} \cdot \mathrm{L}^{-1}\right.$ in $\approx 47.5$ and $\left.\approx 160 \mathrm{mg} \cdot \mathrm{L}^{-1}\right)^{9}$ were prepared by spiking of the stock radish matrix.

$25 \mathrm{mg} \cdot \mathrm{L}^{-1}$ stock radish matrix was prepared by dilution of the filtrate of the $50 \mathrm{mg} \cdot \mathrm{L}^{-1}$ stock radish matrix. PSB49 standards $\left(1.125,2.25,4.5,9,18 \mathrm{mg} \cdot \mathrm{L}^{-1}\right.$ in $\left.\approx 16 \mathrm{mg} \cdot \mathrm{L}^{-1}\right)$ were prepared by spiking of the stock radish matrix. Contrary to the standards, the samples were spiked before the filtration step, not after. It is also worth mentioning that ultrasonication was done before NPs spiking in order to avoid any alteration of the beads suspension.

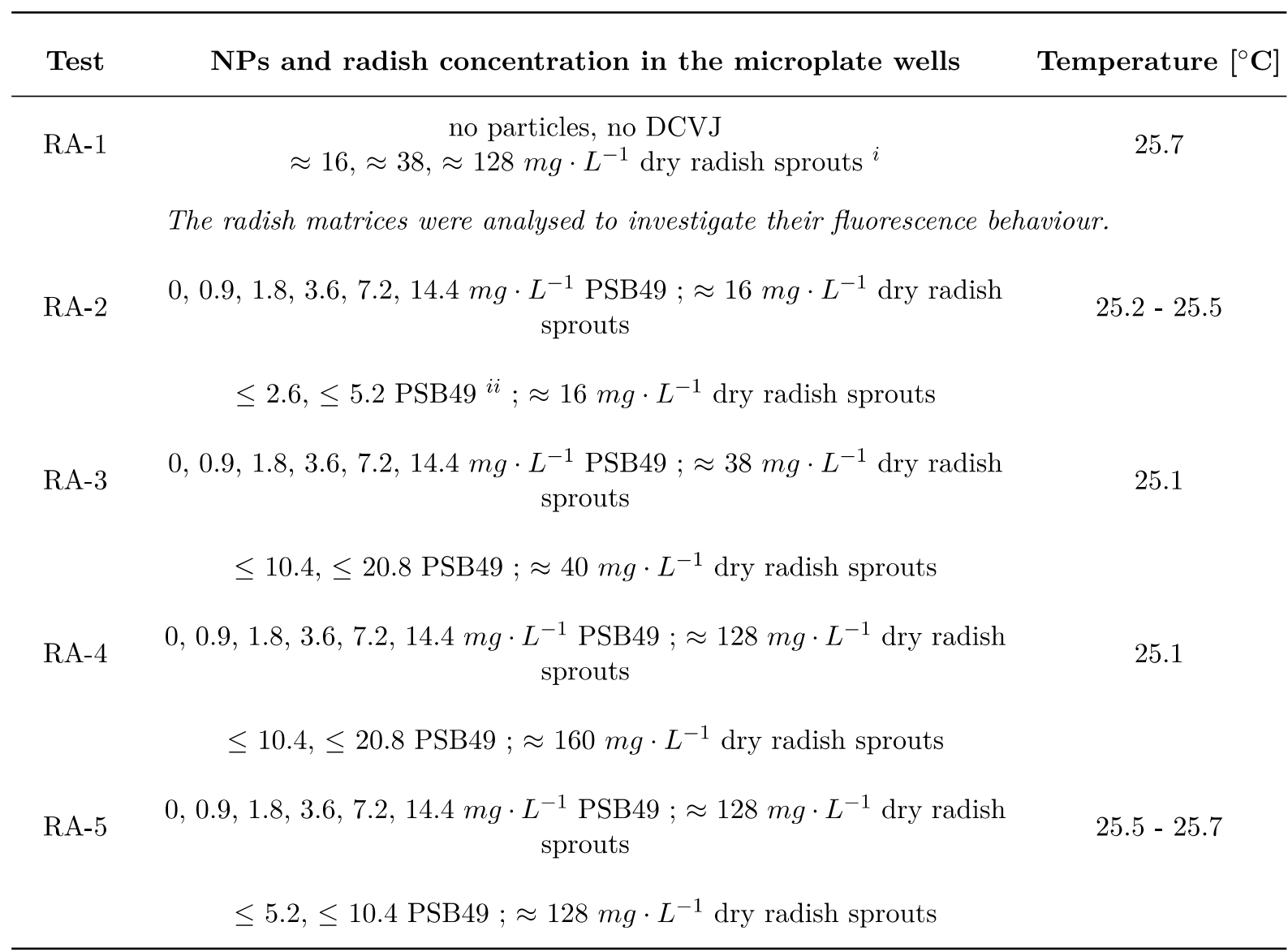

Table S10. Overview of the tests performed with the radish tissues. While the first line of the tests RA-2 to RA-5 describes the standard solutions, the details about the samples are found on the second line. The dry radish sprouts mass concentration calculations do not account for the filtration step, the $\approx$ sign highlights that some undissolved radish tissues were retained on the filter. iiThe samples PSB49 concentration is calculated before the filtering steps, $a \leq$ sign indicates that some of the NPs could have been retained by the filter or the undissolved vegetal tissues.

\footnotetext{
${ }^{9}$ The dry radish sprouts mass concentration calculation does not account for the filtration step, the $\approx$ sign highlights that some undissolved radish tissues were retained on the filter.
} 


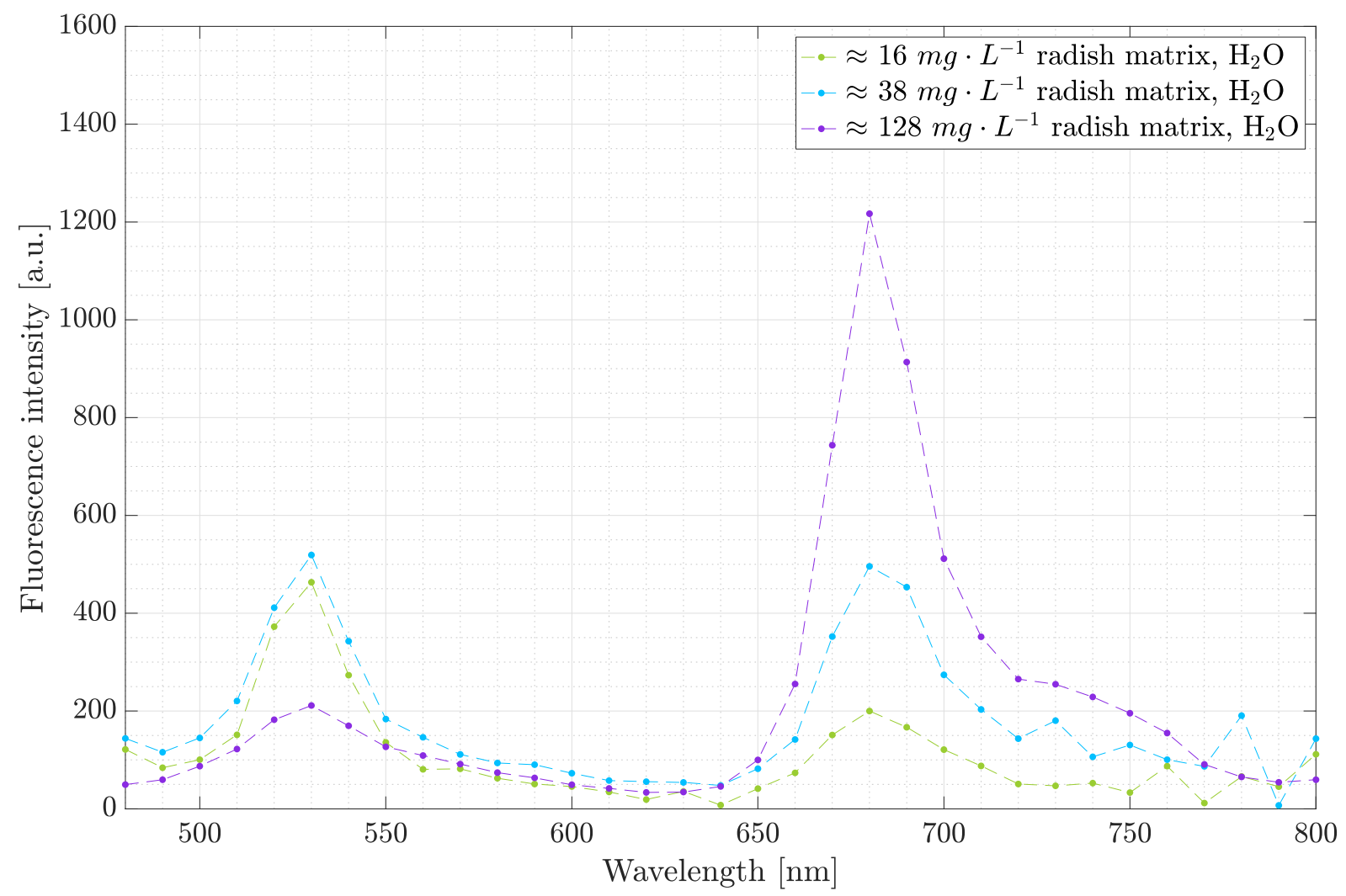

Figure S19. Test RA-1 - Fluorescence spectra arising from radish sprouts in $\mathrm{H}_{2} \mathrm{O}\left(\approx 16, \approx 38, \approx 128 \mathrm{mg} \cdot \mathrm{L}^{-1}\right.$ in the microplate wells). The dry radish sprouts mass concentration calculations do not account for the filtration step, the $\approx$ sign highlights that some undissolved radish tissues were retained on the filter.

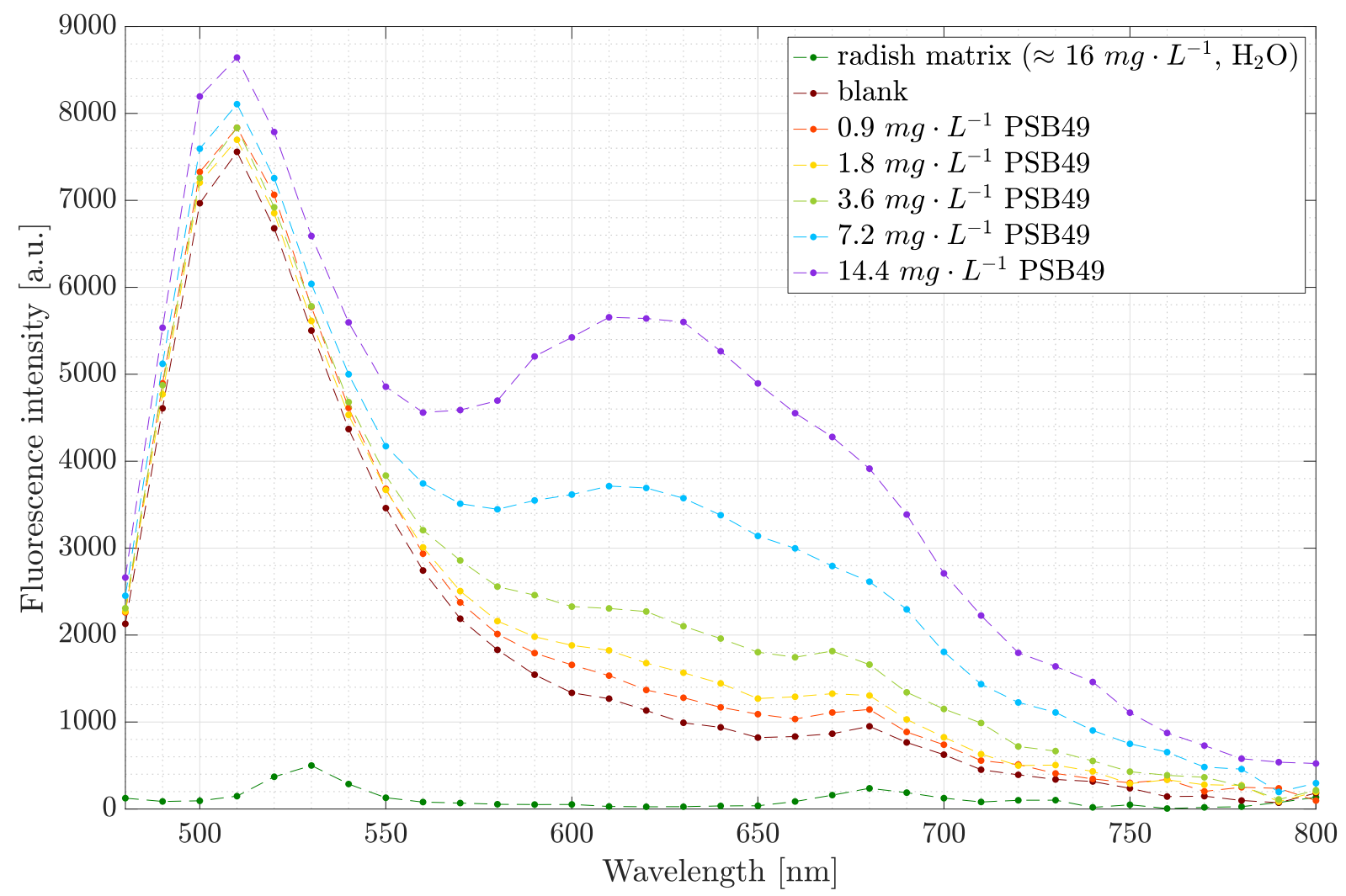

Figure S20. Test RA-2 - Fluorescence spectra arising from DCVJ and the radish sprouts matrix $\left(\approx 16 \mathrm{mg} \cdot \mathrm{L}^{-1}\right) \mathrm{in}$ presence of PSB49 $\left(0.9,1.8,3.6,7.2\right.$ and $\left.14.4 \mathrm{mg} \cdot \mathrm{L}^{-1}\right)$. The blank contains DCVJ $(8 \mu \mathrm{M})$ in the vegetal matrix. 


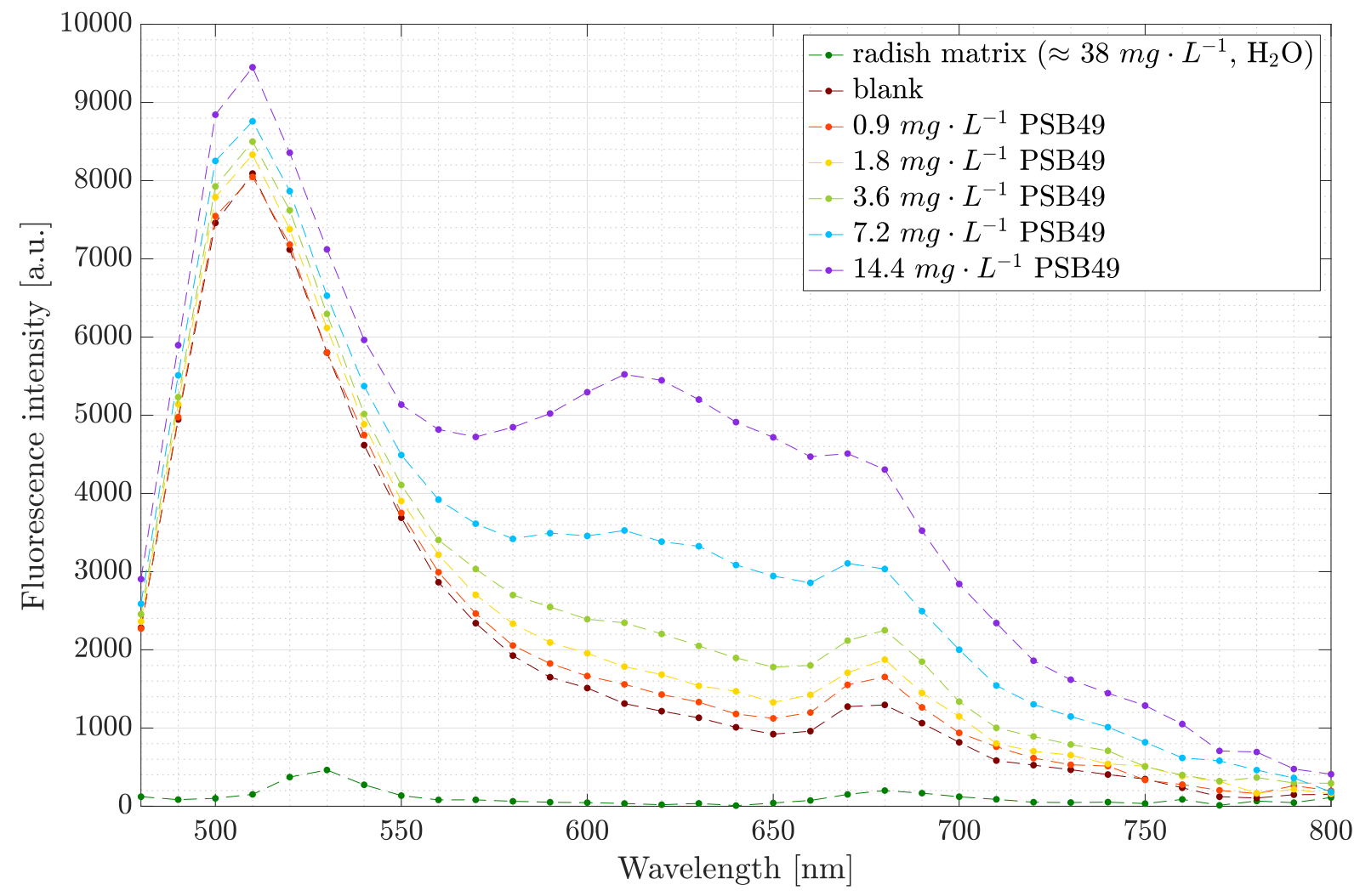

Figure S21. Test RA-3 - Fluorescence spectra arising from DCVJ and the radish sprouts matrix $\left(\approx 38 \mathrm{mg} \cdot \mathrm{L}^{-1}\right)$ in presence of PSB49 $\left(0.9,1.8,3.6,7.2\right.$ and $\left.14.4 \mathrm{mg} \cdot \mathrm{L}^{-1}\right)$. The blank contains DCVJ $(8 \mu \mathrm{M})$ in the vegetal matrix. 


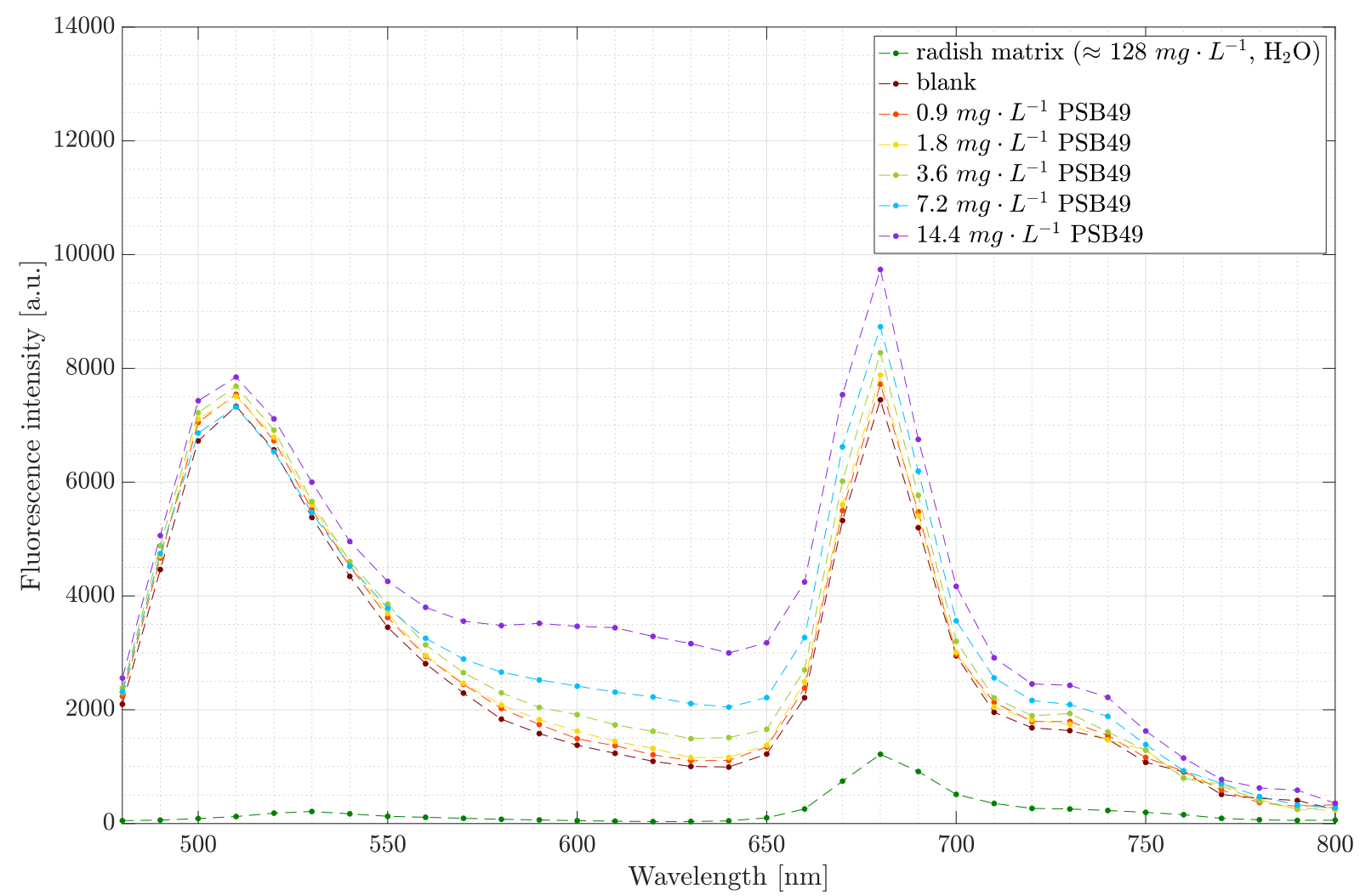

Figure S22. Test RA-4 - Fluorescence spectra arising from DCVJ and the radish sprouts matrix $\left(\approx 128 \mathrm{mg} \cdot \mathrm{L}^{-1}\right)$ in presence of PSB49 $\left(0.9,1.8,3.6,7.2\right.$ and $\left.14.4 \mathrm{mg} \cdot \mathrm{L}^{-1}\right)$. The blank contains DCVJ $(8 \mu \mathrm{M})$ in the vegetal matrix.

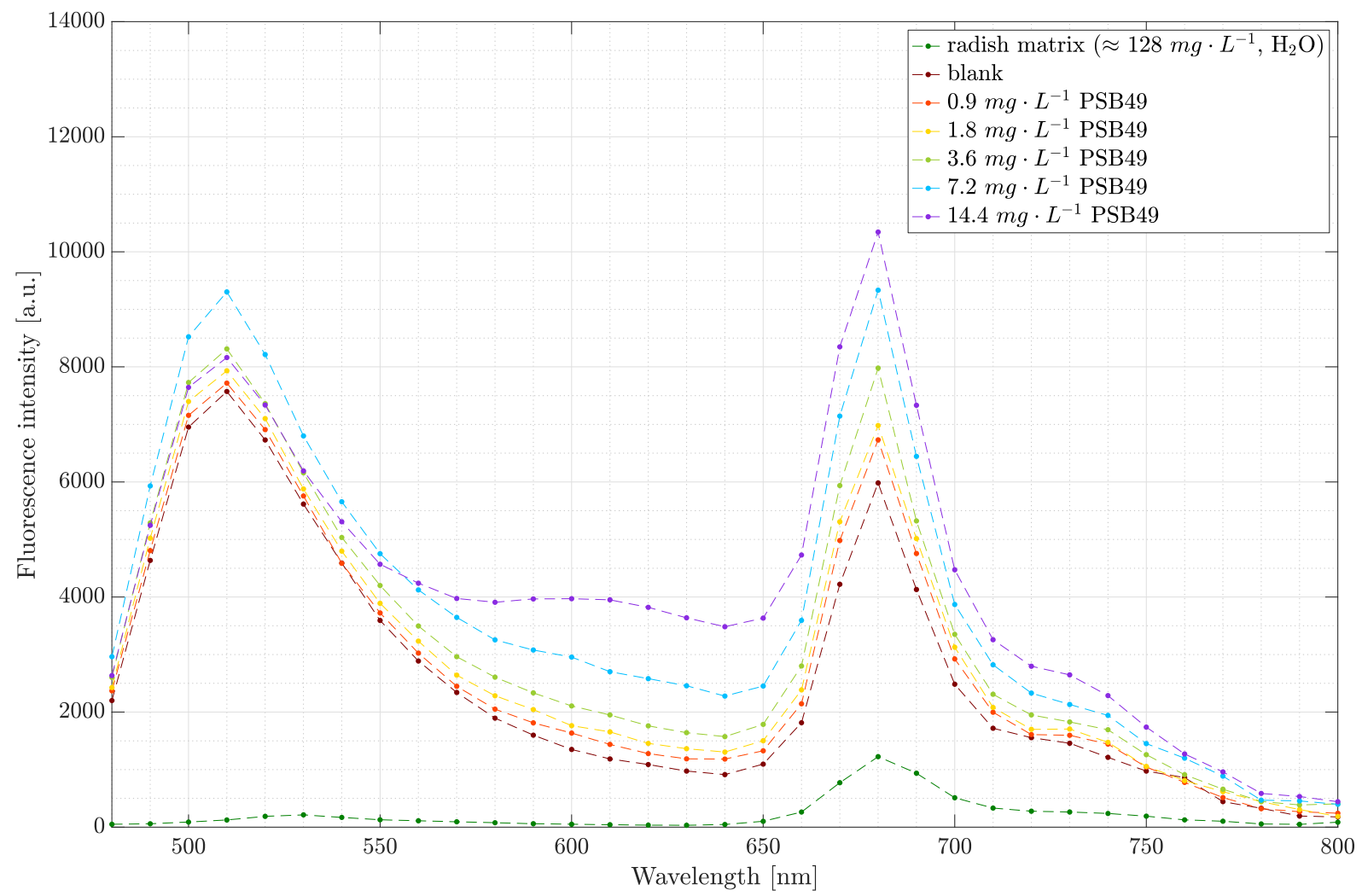

Figure S23. Test RA-5 - Fluorescence spectra arising from DCVJ and the radish sprouts matrix $\left(\approx 128 \mathrm{mg} \cdot \mathrm{L}^{-1}\right)$ in presence of PSB49 $\left(0.9,1.8,3.6,7.2\right.$ and $\left.14.4 \mathrm{mg} \cdot \mathrm{L}^{-1}\right)$. The blank contains DCVJ $(8 \mu \mathrm{M})$ in the vegetal matrix. 


\begin{tabular}{|c|c|c|c|c|c|c|c|c|c|}
\hline Test & $\begin{array}{c}\text { Dry radish } \\
\text { sprouts conc. } \\
{\left[\mathrm{mg} \cdot L^{-1}\right]}\end{array}$ & Y-intercept & Slope & $\mathbf{R}^{2}$ & Sample & $\begin{array}{l}\text { PSB49 } \\
\text { before } \\
\text { filtration } \\
{\left[\mathrm{mg} \cdot L^{-1}\right]}\end{array}$ & $\begin{array}{l}\text { PSB49 max in } \\
\text { the microplate } \\
\text { wells }\left[\mathrm{mg} \cdot \mathrm{L}^{-1}\right]\end{array}$ & $\begin{array}{c}\text { PSB49 } \\
\text { measured } \\
{\left[\mathrm{mg} \cdot L^{-1}\right]}\end{array}$ & $\begin{array}{c}\text { Recovery } \\
\text { rate [\%] }\end{array}$ \\
\hline \multirow[t]{2}{*}{ RA-2 } & $\approx 16$ & $1143 \pm 78$ & $320 \pm 12$ & 0.9948 & RA-2-S1 & 3.25 & 2.60 & $1.7 \pm 0.3$ & 66 \\
\hline & & & & & RA-2-S2 & 6.50 & 5.20 & $3.5 \pm 0.3$ & 67 \\
\hline \multirow[t]{2}{*}{ RA-3 } & $\approx 38$ & $1175 \pm 26$ & $298 \pm 4$ & 0.9993 & RA-3-S1 & 13.00 & 10.40 & $8.61 \pm 0.11$ & 83 \\
\hline & & & & & RA-3-S2 & 26.00 & 20.80 & $15.40 \pm 0.17$ & 74 \\
\hline \multirow[t]{2}{*}{ RA-4 } & $\approx 128$ & $1073 \pm 15$ & $155 \pm 2$ & 0.9991 & RA-4-S1 & 13.00 & 10.40 & $6.25 \pm 0.12$ & 60 \\
\hline & & & & & RA-4-S2 & 26.00 & 20.80 & $24.5 \pm 0.3$ & 118 \\
\hline \multirow[t]{2}{*}{ RA-5 } & $\approx 128$ & $1109 \pm 31$ & $191 \pm 5$ & 0.9976 & RA-5-S1 & 6.50 & 5.20 & $5.89 \pm 0.19$ & 113 \\
\hline & & & & & RA-5-S2 & 13.00 & 10.40 & $12.4 \pm 0.3$ & 119 \\
\hline
\end{tabular}

Table S11. Y-intercept, slope and correlation coefficient of the linear regression at $620 \mathrm{~nm}$ fitting the data points from the vegetal matrix tests RA-2, RA-3, RA-4 and RA-5 $(0,0.9,1.8,3.6,7.2$ and $14.4 \mathrm{mg} \cdot \mathrm{L}-1$ PSB49). The dry radish sprouts mass concentration calculation does not account for the filtration step, the $\approx$ sign highlights that some undissolved radish tissues were retained on the filter. The concentration and recovery rate of PSB49 in the samples from tests RA-2, RA-3, RA-4 and RA-5 are also indicated. The PSB49 concentration termed measured is the value calculated using the measured signal intensity of the sample and the calibration curve at $620 \mathrm{~nm}$ of the same test. The value is the average over the four replicates of a given sample.

\section{S3.2 PSNs quantification in animal samples}

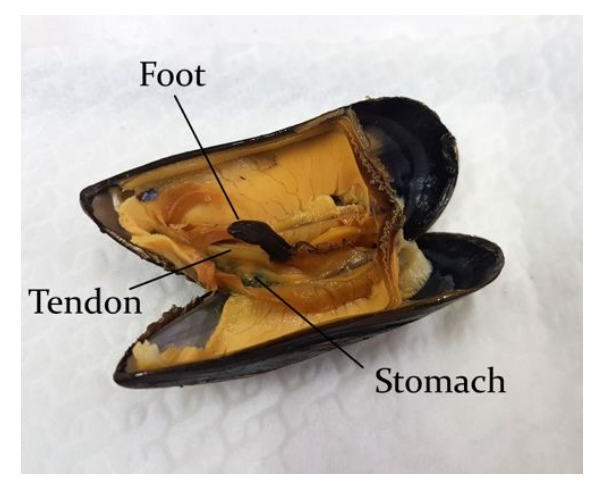

Figure S24. Picture of one defrosted and cooked mussel. The dissected stomach organ is identified below the foot and the tendons. 


\begin{tabular}{|c|c|c|}
\hline Test & $\begin{array}{c}\text { NPs concentration (if present) in the microplate wells } \\
\text { and matrix specification }\end{array}$ & $\begin{array}{l}\text { Temperature } \\
{\left[{ }^{\circ} \mathrm{C}\right]}\end{array}$ \\
\hline \multirow[t]{3}{*}{ MU-1 } & $200 \mu \mathrm{L}$ of $\mathrm{D} 1+50 \mu \mathrm{L}$ DCVJ $(40 \mu \mathrm{M})$ & $26.1-26.3$ \\
\hline & $200 \mu \mathrm{L}$ of $\mathrm{S} 16 \%+50 \mu \mathrm{L} \mathrm{H}{ }_{2} \mathrm{O}$ & \\
\hline & $200 \mu \mathrm{L}$ of $\mathrm{S} 16 \%+50 \mu \mathrm{L}$ DCVJ $(40 \mu \mathrm{M})$ & \\
\hline \multirow[t]{2}{*}{ MU-2 } & no NPs, filtered MSP $\left(\approx \underset{\text { DCVJ }}{\left.16 \mathrm{mg} \cdot \mathrm{L}^{-1}, \mathrm{H}_{2} \mathrm{O}\right), \mathrm{H}_{2} \mathrm{O} \text { instead of }}\right.$ & $25.1-25.2$ \\
\hline & $\begin{array}{l}0,0.9,1.8,3.6,7.2,14.4 \mathrm{mg} \cdot L^{-1} \mathrm{PSB} 49 \\
\text { in filtered } \mathrm{MSP}\left(\approx 16 \mathrm{mg} \cdot L^{-1}, \mathrm{H}_{2} \mathrm{O}\right)\end{array}$ & \\
\hline \multirow[t]{2}{*}{ MU-3 } & no NPs, MSP $\left(16 m g \cdot L^{-1}, \mathrm{H}_{2} \mathrm{O}\right), \mathrm{H}_{2} \mathrm{O}$ instead of DCVJ & $25.1-25.2$ \\
\hline & $\begin{array}{l}0,0.9,1.8,3.6,7.2,14.4 \mathrm{mg} \cdot \mathrm{L}^{-1} \mathrm{PSB} 49 \\
\quad \text { in } \operatorname{MSP}\left(16 \mathrm{mg} \cdot \mathrm{L}^{-1}, \mathrm{H}_{2} \mathrm{O}\right)\end{array}$ & \\
\hline \multirow[t]{2}{*}{ MU-4 } & $\begin{array}{c}\text { no NPs, } 200 \mu \mathrm{L} \text { of digested MSP }\left(\approx 4 g \cdot L^{-1}, \mathrm{D} 1 \mathrm{mix}\right), \mathrm{H}_{2} \mathrm{O} \\
\text { instead of DCVJ }\end{array}$ & $25.5-26.0$ \\
\hline & $8,16 m g \cdot L^{-1} \operatorname{PSB} 49$ in $\operatorname{MSP}\left(\approx 4 g \cdot L^{-1}, \mathrm{D} 1 \mathrm{mix}\right)$ & \\
\hline \multirow[t]{2}{*}{ MU-5 } & $\begin{array}{c}\text { no NPs, } 200 \mu \mathrm{L} \text { of digested } \mathrm{MSP}\left(\approx 4 g \cdot L^{-1}, \mathrm{KOH}\right), \mathrm{H}_{2} \mathrm{O} \\
\text { instead of DCVJ }\end{array}$ & $26.1-26.5$ \\
\hline & $8,16 m g \cdot L^{-1} \mathrm{PSB} 49$ in $\operatorname{MSP}\left(\approx 4 g \cdot L^{-1}, \mathrm{KOH}\right)$ & \\
\hline \multirow[t]{3}{*}{ MU-6 } & $\begin{array}{c}\text { no NPs, } 200 \mu \mathrm{L} \text { of digested MSP }\left(\approx 4 g \cdot L^{-1}, \mathrm{D} 1 \mathrm{mix}\right), \mathrm{H}_{2} \mathrm{O} \\
\text { instead of DCVJ }\end{array}$ & 25.1 \\
\hline & $\begin{array}{c}0,0.9,1.8,3.6,7.2,14.4 \mathrm{mg} \cdot L^{-1} \mathrm{PSB} 49 \text { in } \mathrm{MSP}\left(\approx 4 g \cdot L^{-1}\right. \\
\mathrm{D} 1 \mathrm{mix})\end{array}$ & \\
\hline & $4,8,12,16 \mathrm{mg} \cdot L^{-1} \mathrm{PSB} 49$ in $\operatorname{MSP}\left(\approx 4 g \cdot L^{-1}, \mathrm{D} 1 \mathrm{mix}\right)$ & \\
\hline \multirow[t]{3}{*}{ MU-7 } & $\begin{array}{c}\text { no NPs, } 200 \mu \mathrm{L} \text { of digested } \mathrm{MSP}\left(\approx 4 g \cdot L^{-1}, \mathrm{KOH}\right), \mathrm{H}_{2} \mathrm{O} \\
\text { instead of DCVJ }\end{array}$ & 25.1 \\
\hline & $\begin{array}{c}0,0.9,1.8,3.6,7.2,14.4 \mathrm{mg} \cdot \mathrm{L}^{-1} \mathrm{PSB} 49 \text { in } \operatorname{MSP}\left(\approx 4 g \cdot L^{-1},\right. \\
\mathrm{KOH})\end{array}$ & \\
\hline & $4,8,12,16 \mathrm{mg} \cdot L^{-1} \mathrm{PSB} 49$ in $\mathrm{MSP}\left(\approx 4 g \cdot L^{-1}, \mathrm{KOH}\right)$ & \\
\hline
\end{tabular}

Table S12. Overview of the tests performed with the mussel's tissues. MSP stands for mussel stomach powder (obtained after cooking, dissecting and freeze-drying mussels). Its mass concentration calculation does not account for the filtration step, the $\approx$ sign indicates that some pieces were removed during centrifugation. The samples prepared for tests MU-4 (8 and $16 \mathrm{mg} \cdot \mathrm{L}^{-1} \mathrm{PSB} 49 \mathrm{in} \approx 4 \mathrm{~g} \cdot \mathrm{L}^{-1} \mathrm{MSP}$ digested with D1 mix) and MU-5 (8 and $16 \mathrm{mg} \cdot \mathrm{L}^{-1}$ $\mathrm{PSB} 49$ in $\approx 4 \mathrm{~g} \cdot \mathrm{L}^{-1} \mathrm{MSP}$ digested with $\mathrm{KOH}$ ) were measured again during test MU-6 and MU-7. Whenever DCVJ is present, its concentration is $8 \mu \mathrm{M}$ in the microplate wells. 


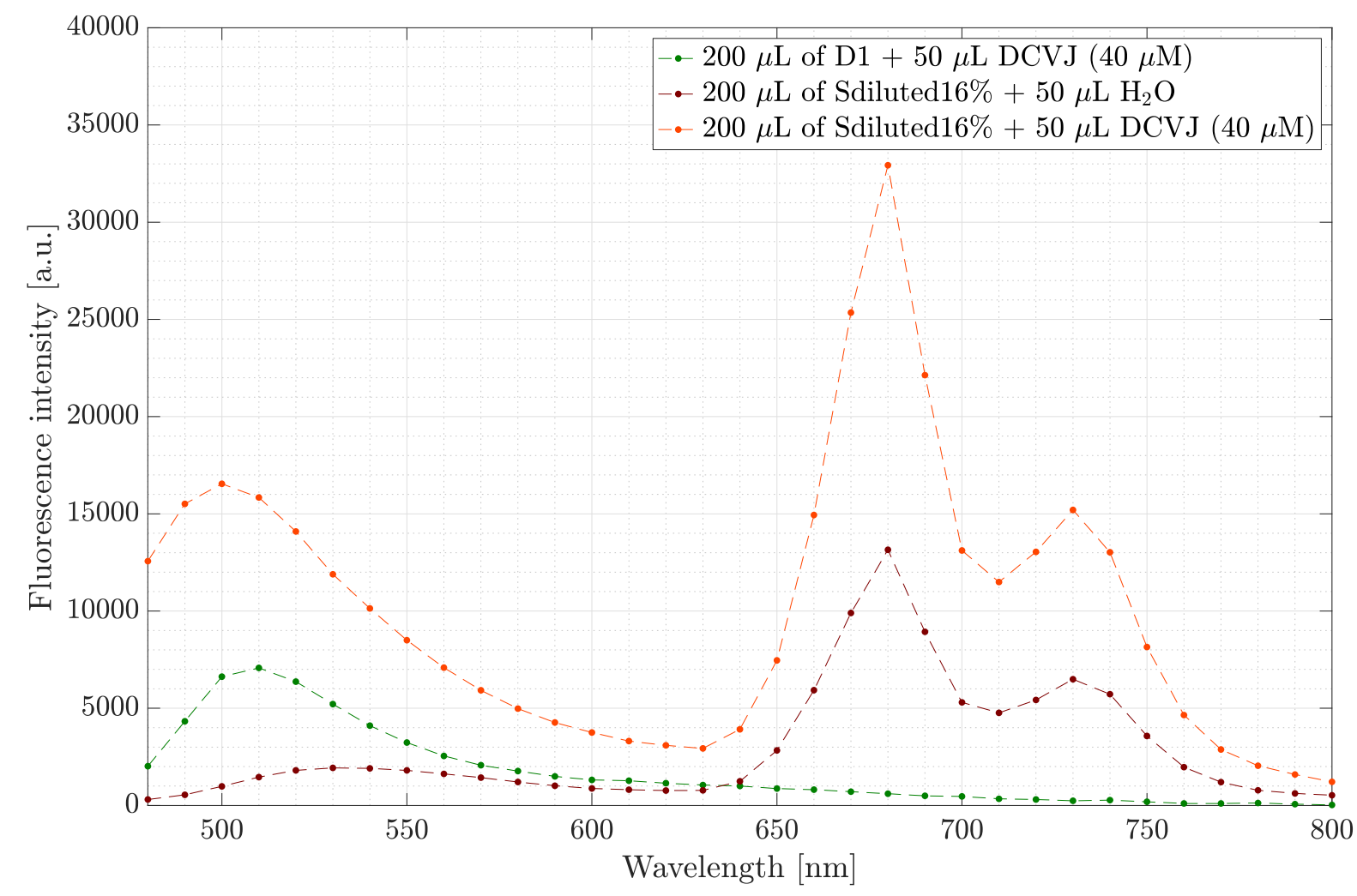

Figure S25. Test MU-1 - Fluorescence spectrum arising from DCVJ in the D1 mix used to solubilize the mussel paste and emission of the Sdiluted $16 \%$ supernatant in absence or presence of DCVJ ( $8 \mu \mathrm{M}$ in the microplate wells). 

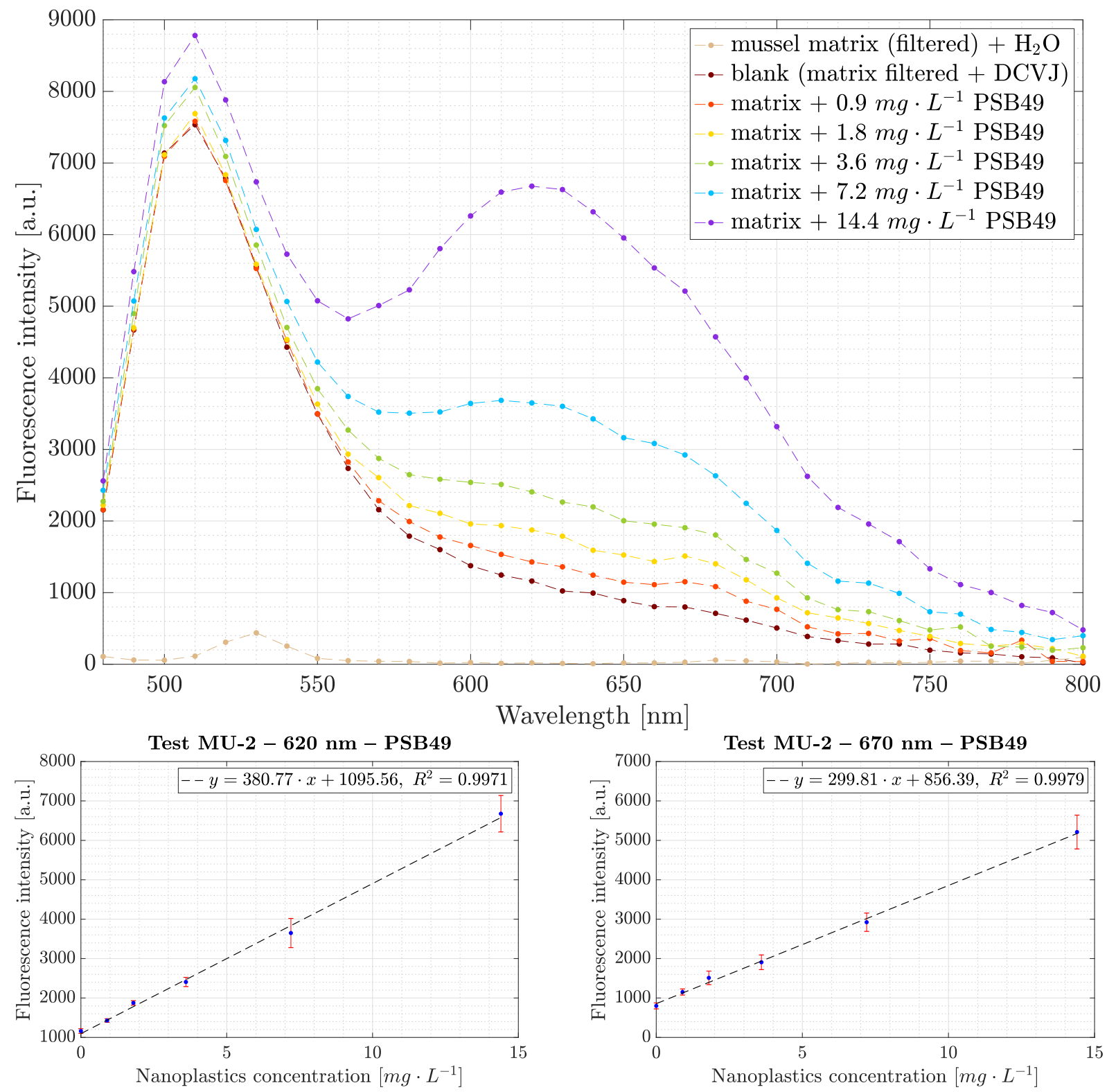

Figure S26. Test MU-2 - Fluorescence spectrum arising from DCVJ in filtered MSP matrix prepared at $16 \mathrm{mg} \cdot \mathrm{L}^{-1}$ in $\mathrm{H}_{2} \mathrm{O}$ and spiked with PSB49 $\left(0,0.9,1.8,3.6,7.2\right.$ and $\left.14.4 \mathrm{mg} \cdot \mathrm{L}^{-1}\right)$. The plot of the signal intensity as a function of PSB49 concentration at $620 \mathrm{~nm}$ and $670 \mathrm{~nm}$ is also given and includes the linear regression curve. 

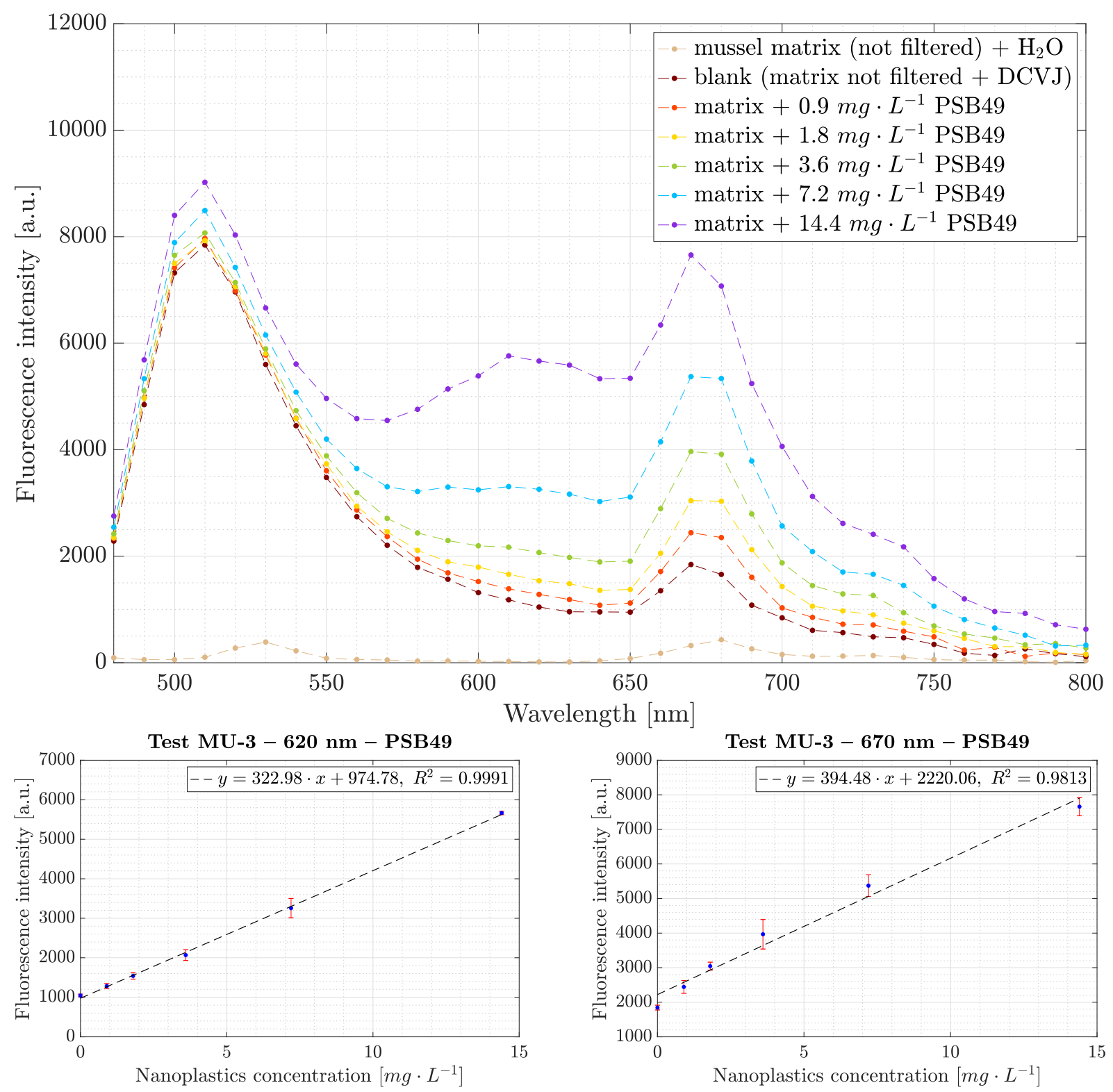

Figure S27. Test MU-3 - Fluorescence spectrum arising from DCVJ in non-filtered MSP matrix prepared at 16 $\mathrm{mg} \cdot \mathrm{L}^{-1}$ in $\mathrm{H}_{2} \mathrm{O}$ and spiked with PSB49 $\left(0,0.9,1.8,3.6,7.2\right.$ and $\left.14.4 \mathrm{mg} \cdot \mathrm{L}^{-1}\right)$. The plot of the signal intensity as a function of PSB49 concentration at $620 \mathrm{~nm}$ and $670 \mathrm{~nm}$ is also given and includes the linear regression curve. 

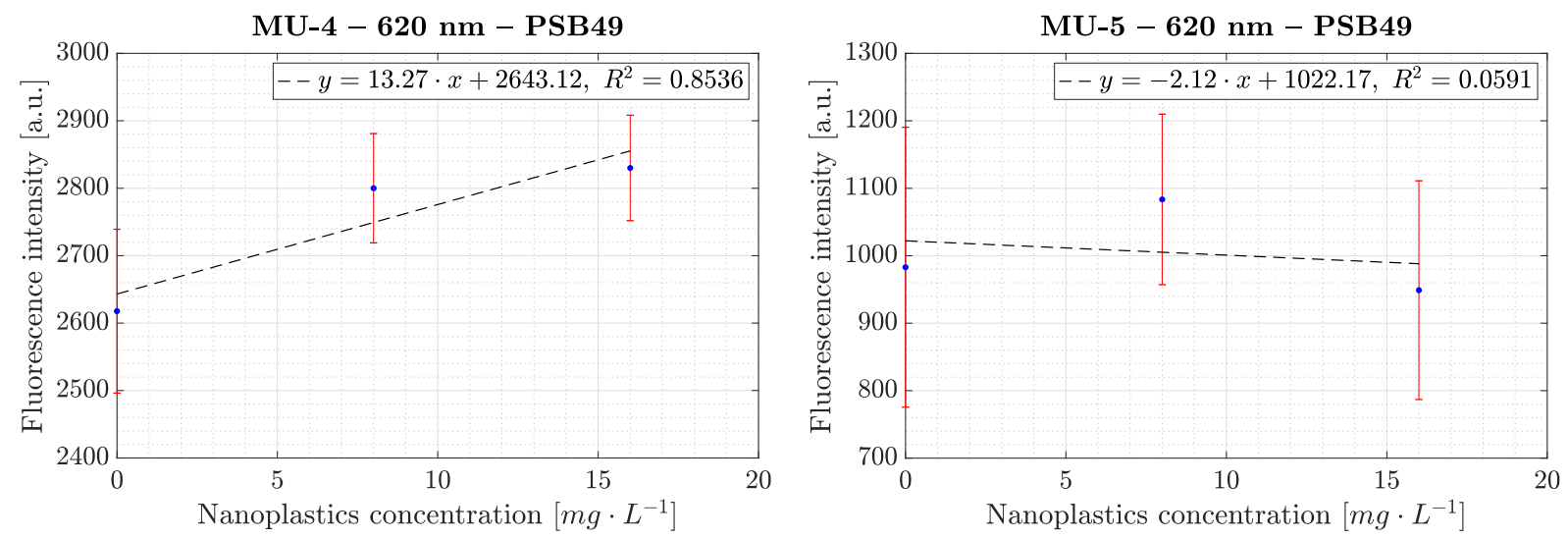

Figure S28. Fluorescence intensity of DCVJ as a function of PSB49 samples concentration $\left(0,4\right.$ and $8 \mathrm{mg} \cdot \mathrm{L}^{-1}$ in the microplate wells, excluding the potential loss during centrifugation). The samples were prepared by spiking and digesting $5 \mathrm{~g} \cdot \mathrm{L}^{-1} \mathrm{MSP}$ for 3 hours in either mix D1 (left, test MU-4) or $\mathrm{KOH} 10 \%$ (right, test MU-5).

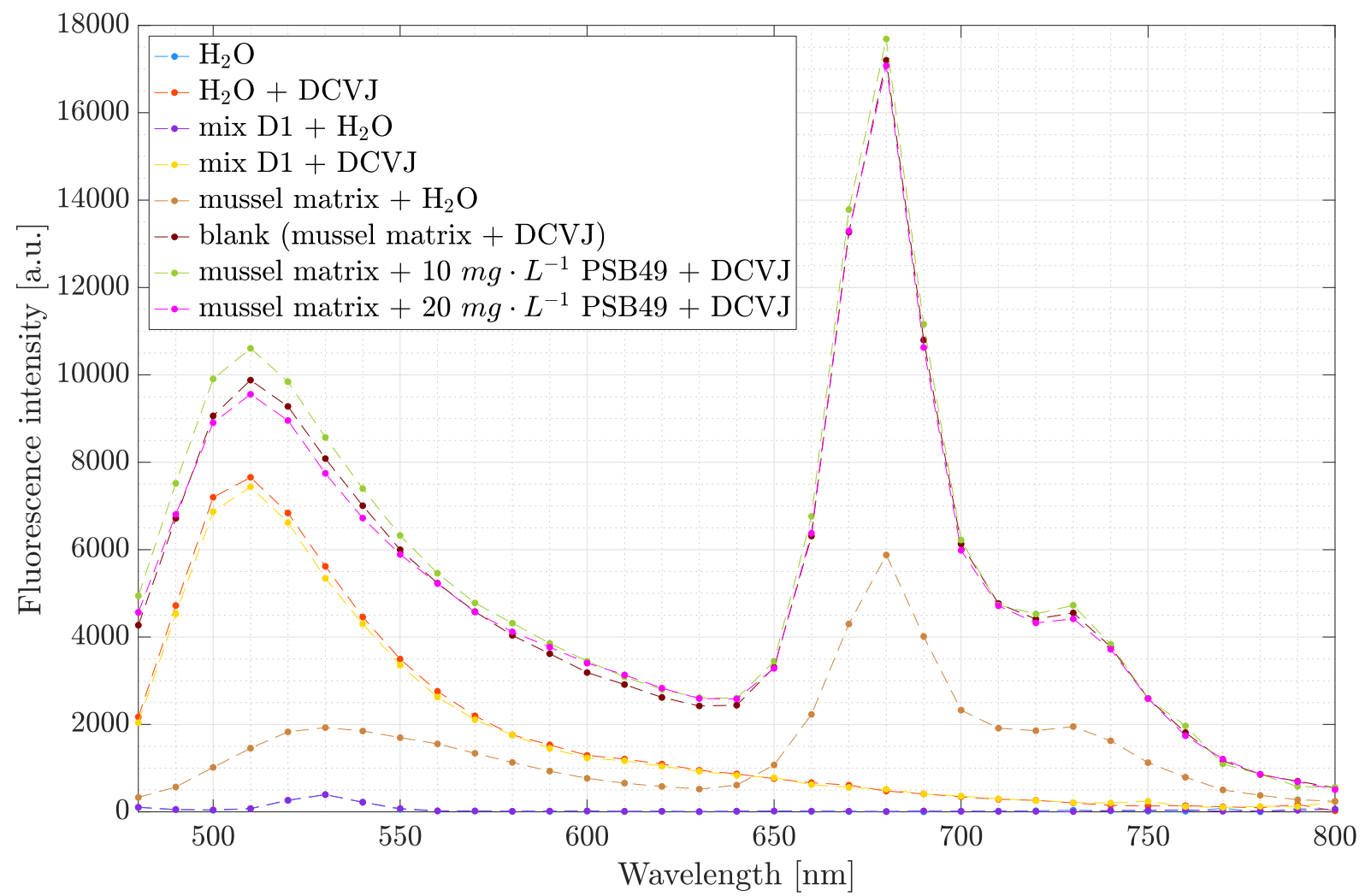

Figure S29. Test MU-4 - Fluorescence spectrum of DCVJ in presence of the mussel matrix digested with the D1 mix and PSB49 samples $\left(0,8\right.$ and $16 \mathrm{mg}^{-\mathrm{L}^{-1}}$ in the microplate wells, excluding the potential loss during centrifugation). The samples were prepared by spiking and digesting $5 \mathrm{~g} \cdot \mathrm{L}^{-1} \mathrm{MSP}$ in the D1 mix for 3 hours. The emission spectrum of water, DCVJ in presence of water and DCVJ in presence of the D1 mix are also displayed. As previously, $50 \mu \mathrm{L}$ of DCVJ $(40 \mu \mathrm{M}, \mathrm{MeOH})$ was added to 200 of $\mu \mathrm{L}$ analyte. The same proportions are used when DCVJ is replaced by $50 \mu \mathrm{L}$ of water. 


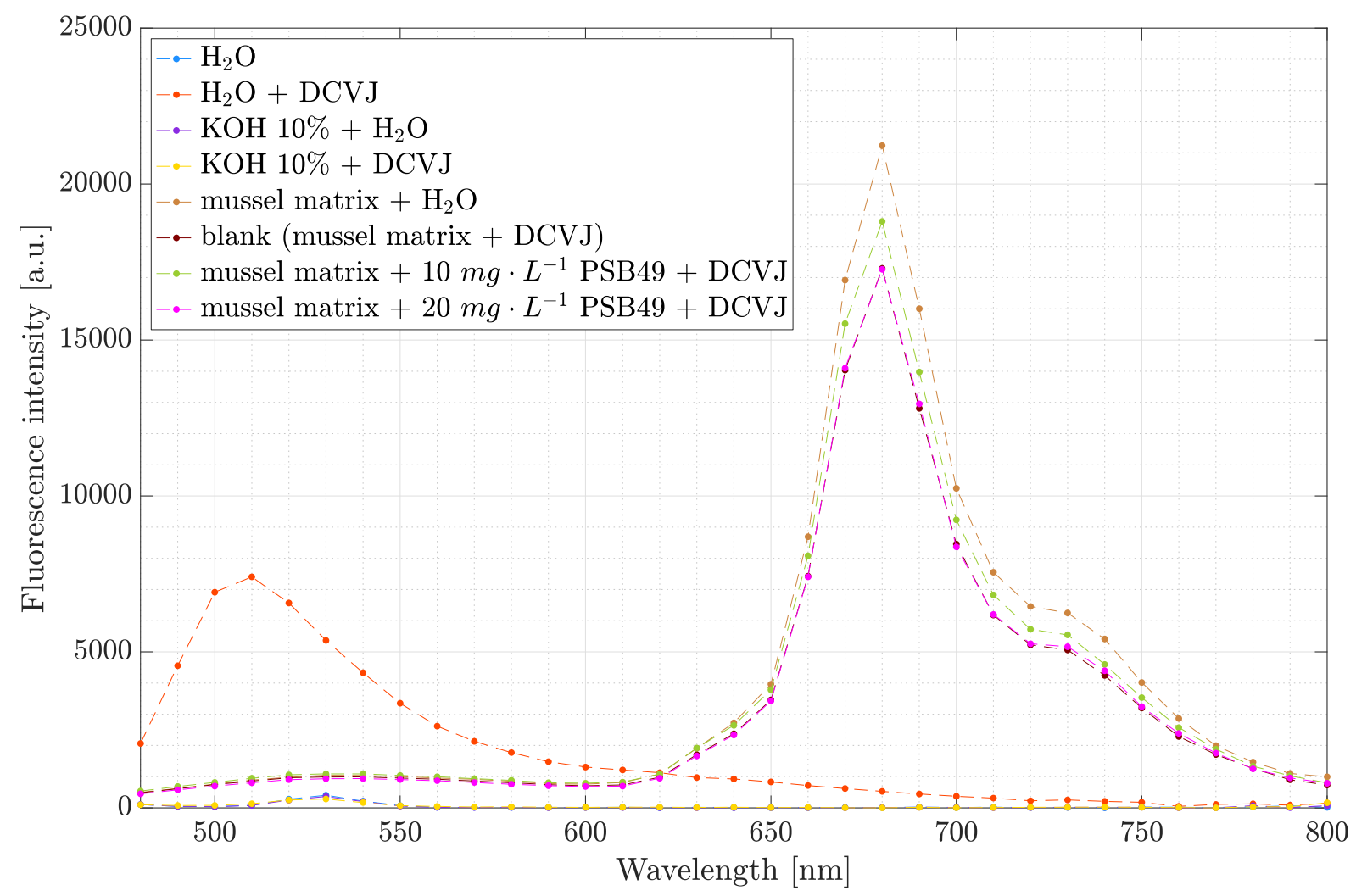

Figure S30. Test MU-5 - Fluorescence spectrum of DCVJ in presence of mussel matrix digested with $\mathrm{KOH} 10 \%$ and PSB49 samples $\left(0,8\right.$ and $16 \mathrm{mg} \cdot \mathrm{L}^{-1}$ in the microplate wells, excluding the potential loss during centrifugation). The samples were prepared by spiking and digesting $5 \mathrm{~g} \cdot \mathrm{L}^{-1} \mathrm{MSP}$ in $\mathrm{KOH} 10 \%$ for 3 hours. The emission spectrum of water, DCVJ in presence of water and DCVJ in presence of $\mathrm{KOH} 10 \%$ are also displayed. As previously, $50 \mu \mathrm{L}$ of DCVJ $(40 \mu \mathrm{M}, \mathrm{MeOH})$ was added to 200 of $\mu \mathrm{L}$ analyte. The same proportions are used when DCVJ is replaced by $50 \mu \mathrm{L}$ of water. The blank spectrum (maroon curve) is mostly hidden under the spectrum arising from the mussel matrix mixed with $20 \mathrm{mg} \cdot \mathrm{L}^{-1} \mathrm{PSB} 49$ and DCVJ (pink curve). 


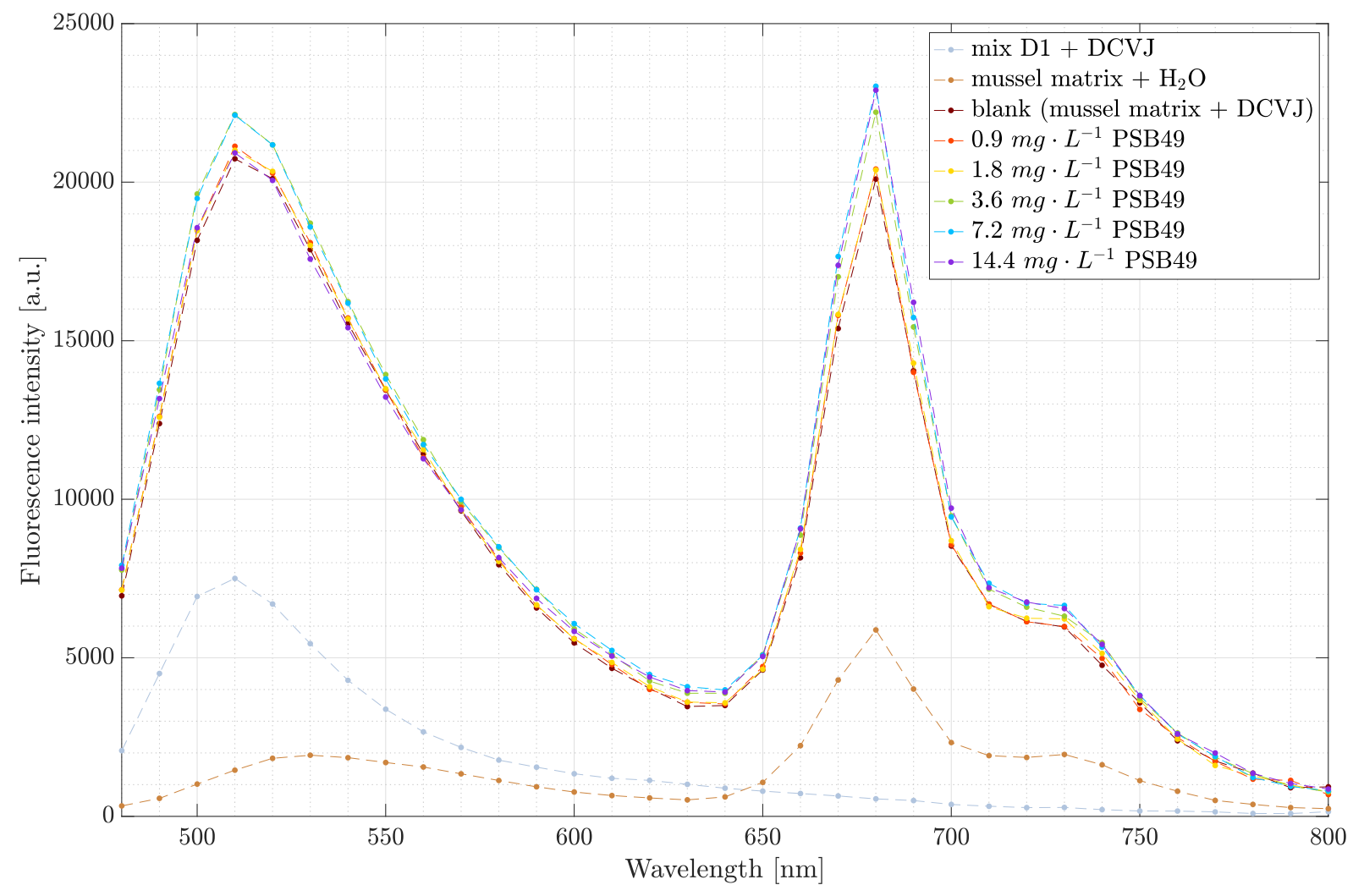

Figure S31. Test MU-6 - Fluorescence spectra of DCVJ $(8 \mu \mathrm{M})$ as a function of PSB49 standards $(0,0.9,1.8,3.6$, 7.2 and $\left.14.4 \mathrm{mg} \cdot \mathrm{L}^{-1}\right)$. The supernatant of the centrifuged digested matrix $\left(5 \mathrm{~g} \cdot \mathrm{L}^{-1} \mathrm{MSP}\right.$ in mix D1, $24 \mathrm{~h}$ digestion in a water bath) free from NPs was spiked with PSB49 to obtain the standards. The concentration of MSP in the microplate wells is $\approx 4 \mathrm{~g} \cdot \mathrm{L}^{-1}$. 


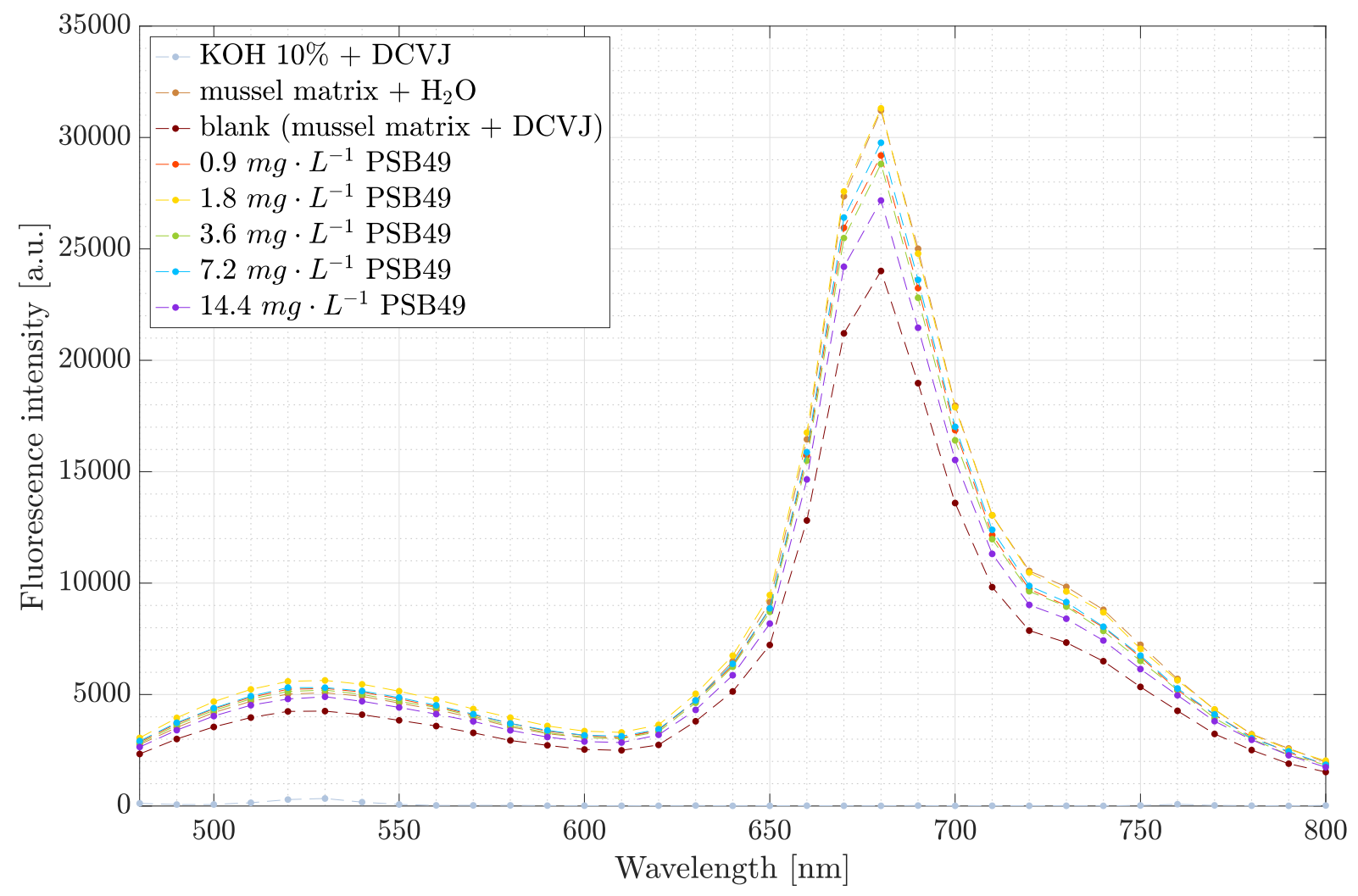

Figure S32. Test MU-7 - Fluorescence spectra of DCVJ $(8 \mu \mathrm{M})$ as a function of PSB49 standards $(0,0.9,1.8,3.6$, 7.2 and $\left.14.4 \mathrm{mg} \cdot \mathrm{L}^{-1}\right)$. The supernatant of the centrifuged digested matrix $\left(5 \mathrm{~g} \cdot \mathrm{L}^{-1} \mathrm{MSP}\right.$ in $\mathrm{KOH} 10 \%, 24 \mathrm{~h}$ digestion in a water bath) free from NPs was spiked with PSB49 to obtain the standards. The concentration of MSP in the microplate wells is $\approx 4 \mathrm{~g} \cdot \mathrm{L}^{-1}$.
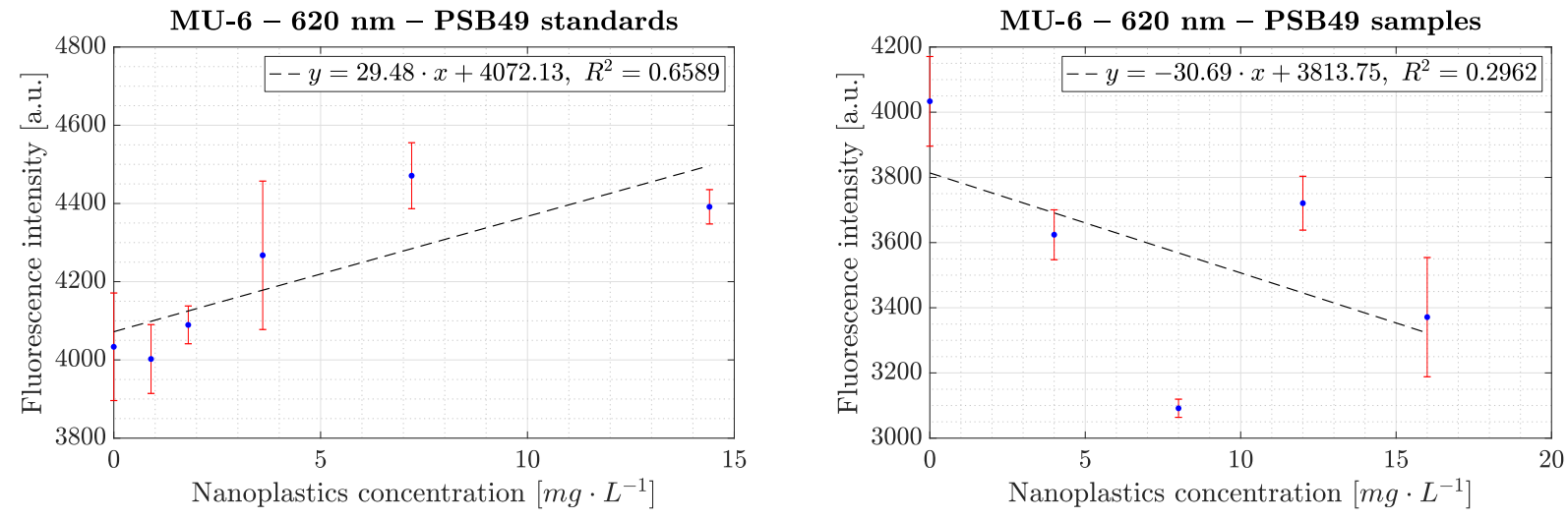

Figure S33. Test MU-6 - Fluorescence intensity as a function of either PSB49 standards $(0,0.9,1.8,3.6,7.2$ and $\left.14.4 \mathrm{mg} \cdot \mathrm{L}^{-1}\right)$ concentration (left plot) or PSB49 samples $\left(0,4,8,12\right.$ and $16 \mathrm{mg} \cdot \mathrm{L}^{-1}$ in the microplate wells, excluding the potential loss during centrifugation) concentration (right plot). The samples were prepared by spiking the matrix ( $5 \mathrm{~g}^{\cdot \mathrm{L}^{-1}} \mathrm{MSP}$ in mix D1) before $24 \mathrm{~h}$ of digestion in a water bath. The supernatant of the centrifuged digested matrix free from NPs was spiked with PSB49 to obtain the standards. The concentration of MSP in the microplate wells is $\approx 4 \mathrm{~g} \cdot \mathrm{L}^{-1}$. 

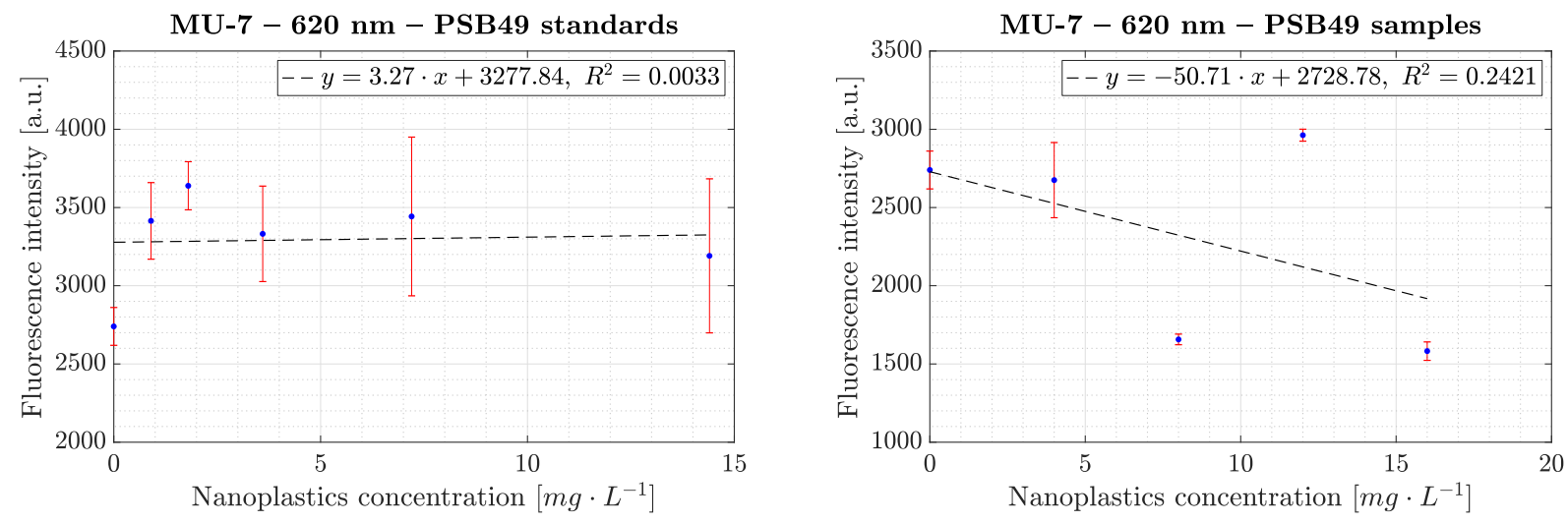

Figure S34. Test MU-7 - Fluorescence intensity as a function of either PSB49 standards $(0,0.9,1.8,3.6,7.2$ and $\left.14.4 \mathrm{mg} \cdot \mathrm{L}^{-1}\right)$ concentration (left plot) or PSB49 samples $\left(0,4,8,12\right.$ and $16 \mathrm{mg} \cdot \mathrm{L}^{-1}$ in the microplate wells, excluding the potential loss during centrifugation) concentration (right plot). The samples were prepared by spiking the matrix ( $5 \mathrm{~g} \cdot \mathrm{L}^{-1} \mathrm{MSP}$ in $\left.\mathrm{KOH} 10 \%\right)$ before $24 \mathrm{~h}$ of digestion in a water bath. The supernatant of the centrifuged digested matrix free from NPs was spiked with PSB49 to obtain the standards. The concentration of MSP in the microplate wells is $\approx 4 \mathrm{~g} \cdot \mathrm{L}^{-1}$. 